\title{
On the Aerodynamics of an Enclosed-Wheel Racing Car: an assessment and proposal of add-on devices for a fourth, high-performance configuration of the DrivAer model
}

\author{
R. F. Soares, S. M. Goñalons Olives, A. P. Knowles, K. P. Garry, J. C. Holt \\ Applied Aerodynamics Group, Cranfield University, UK
}

\begin{abstract}
A modern benchmark for passenger cars - DrivAer model - has provided significant contributions to aerodynamics-related topics in automotive engineering, where three categories of passenger cars have been successfully represented. However, a reference model for highperformance car configurations has not been considered appropriately yet. Technical knowledge in motorsport is also restricted due to competitiveness in performance, reputation and commercial gains. The consequence is a shortage of open-access material to be used as technical references for either motorsport community or academic research purposes.
\end{abstract}

In this paper, a parametric assessment of race car aerodynamic devices are presented into four groups of studies. These are: (i) forebody strakes (dive planes), (ii) front bumper splitter, (iii) rear-end spoiler, and (iv) underbody diffuser. The simplified design of these add-ons focuses on the main parameters (such as length, position, or incidence), leading to easier manufacturing for experiments and implementation in computational studies. Consequently, a proposed model aims to address enclosed-wheel racing car categories, adapting a simplified, $35 \%$ scaled-model DrivAer Fastback shape (i.e. smooth underbody, no wheels, and with side mirrors).

Experimental data were obtained at the $8 \mathrm{ft} \times 6 \mathrm{ft}$ Cranfield Wind Tunnel using an internal balance for force and moment measurements. The aerodynamic performance of each group of add-on was assessed individually in a range of ride heights over a moving belt. All cases represent the vehicle at a zero-yaw condition, Reynolds number (car length-based) of $4.2 \times 10^{6}$ and Mach number equal to 0.12 . The proposed high-performance configuration (DrivAer $h p-F)$ was tested and a respective Reynolds number dependency study is also provided.

In line with the open-access concept of the DrivAer model, the CAD geometry and experimental data will be made available online to the international community to support independent studies.

\section{INTRODUCTION}

Aerodynamic design has played an important role in the evolution of motorsport. In earlier stages of race car design, the optimisation

Page 1 of 27 process focused on the whole body rather than specific parts. The engineering goal was to minimise drag resistance in order to achieve higher top speed and successive speed records. That generation of automotive bodies is currently referred as streamlined shapes. In 1954, two different design approaches were adopted in the respective F1 championship: open-wheel (e.g. Maserati 250F) and enclosed-wheel (e.g. Mercedes-Benz W196s) streamlined racing cars.

Traditional racing tracks were mostly based on long straight line sectors (e.g. Autodromo Nazionale Monza) and undesired lift generation seemed not to be a relevant issue yet. However, drag reduction only due to body optimisation only would find its technical limits, and racing cars became too fast even for large-radius turning sectors. A new age of racing car aerodynamics born when higher speed in the corners was also pursuit.

In order to keep improving lap times, cars need to bear higher lateral acceleration. Tyres have the only contact surface supporting the resulting load, which is proportional to two parameters: grip coefficient and normal load applied. If changes in tyre compound is not considered, negative lift (usually referred as 'downforce' in motorsport) is the main approach to extend the adherence limit by adding this extra normal load to the vehicle weight. The use of wingshaped components (i.e. aerofoils with only purpose of downforce

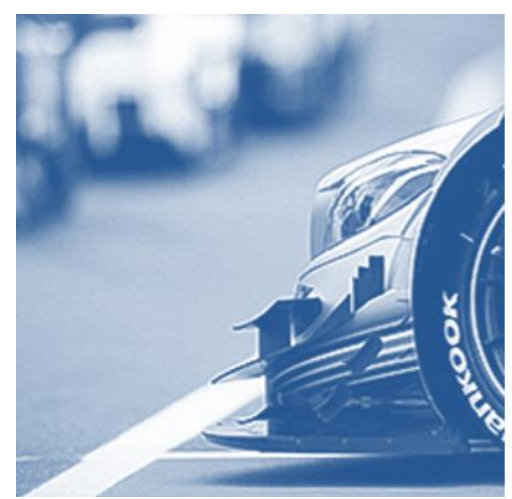

(a)

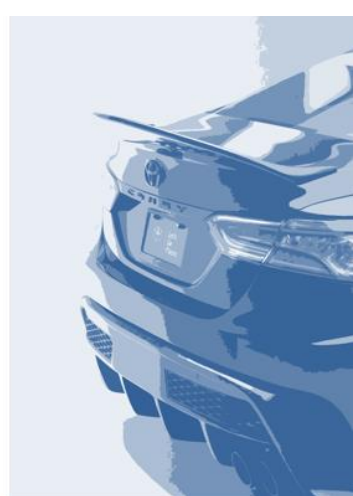

(b)
Figure 1. Examples of aerodynamic devices used on high-performance car models: (a) forebody strakes and bumper splitter (DTM racing car, [1]); (b) rear-end spoiler and diffuser (street-legal sport car, [2]). 
generation) as introduced in $1967 \mathrm{~F} 1$ racing car is a milestone in motorsport aerodynamics.

In the majority of current racing car categories, a few aerodynamic devices can be quickly identified. Figure 1 illustrates examples of state-of-art aerodynamic devices in high-performance cars. Unfortunately, most of the technical information from technological developments in motorsport are restricted to teams and private research centres. This scenario has led to a shortage of open-access material to be used as technical references for either motorsport community or academic research purposes.

This paper presents experimental studies of simple add-ons in motorsport aerodynamics, which focus on enclosed-wheel racing cars. The aerodynamic loading characteristics of four types of aerodynamic devices (exemplified in Figure 1) were assessed as a function of ride height and their respective parameters. A high-performance configuration model (DrivAer $h p-F$ ) is also proposed for further experimental and computational studies.

\section{TECHNICAL BACKGROUND}

\section{Front bumper splitter and forebody strakes}

A splitter is defined in this instance as an air dam that protrudes in front of the bumper and divides the incoming flow. Katz [3] described the fundamental aerodynamic mechanism of splitters in terms of the creation of stagnation point above the plate, such that the increase in pressure on its upper surface generates downforce.

Singh [4] investigated the effect of varying splitter length affected on downforce using a NASCAR configuration. The study examined aerodynamic load increments measured when replacing a baseline splitter $(150 \mathrm{~mm})$ with a shorter version $(100 \mathrm{~mm})$, both fixed $50 \mathrm{~mm}$ off the ground. Using a fixed ground wind tunnel simulation (woGS), it was shown that front and rear downforce reduced as the splitter size reduced, the majority of the reduction (90\%) at the front axle. Using a moving ground simulation with rotating wheels mitigated the splitter length sensitivity by reducing variation on the front downforce and generating a small increment of rear downforce with the shorter splitter. The variation in drag coefficient $\left(C_{D}\right)$ was less than 0.005 for either ground condition.

Katz [5] assessed low-cost devices, including a splitter plate, to increase downforce on a sports car model is was seen that the splitter was one of the most efficient devices, and the experimental data suggest an increment of nominally $\Delta C_{L}=-0.10$ with a marginal drag penalty (e.g. $\left.\Delta C_{D}<|0.02|\right)$.

There is relatively little information in the open literature relating to the quantitative performance of forebody strakes (also known as dive planes or dive vanes). Katz [3] suggested that the performance of simple flat plates could be used to estimate the performance of strakes on an automotive body. The author predicted that a pair of forebody strakes (one on each side) would generate $\Delta C_{L} \sim-0.03$ and $\Delta C_{D} \sim 0.01$.

\section{Rear Spoilers}

Despite their relatively low aerodynamic efficiency if compared to rear wing [6], rear-end spoilers are widely used in race car competitions due to design simplicity and effectiveness. For racing applications, rear-end spoilers have been used in enclosed-wheels categories such as NASCAR. A Particle Image Velocimetry (PIV) study performed by Hellman et al. [7] on a NASCAR Car of Tomorrow (COT) rear-end spoiler was compared to a case with a rear wing. This showed that more downforce is generated with the spoiler due to a higher flow deflection.

The performance of rear mounted device mutually dependant to the geometry of the vehicle. Le Good et al. [8] performed a numerical study, based on Detached Eddy Simulation (DES) modelling, on a series of spoiler design. Both backlight angle and spoiler height have impact on the aerodynamic performance of a DrivAer Fastback model. It was demonstrated that simple add-ons can create an increase of downforce, usually accompanied by a drag penalty. However, specific integration of a spoiler into the rear geometry can result in a reduction in drag coefficient, see for example Katz [3]. The position of the spoiler can affect the forebody stagnation line, moving it upwards and increasing flow rate in the underbody.

A numerical study performed by Cheng and Mansor [9] with the Ahmed model [10] included a simple rear spoiler that helped to identify the expected trends of making this type of modification. It was found that downforce increases as the spoiler angle rises due to flow deceleration upstream of this device. This is accompanied by a considerable increase in drag due to flow separation downstream of the spoiler. In a similar study, Fukuda et al. [11] showed the effect of a rear-end spoiler in the boot deck of the Ahmed body, with a relatively small drag penalty compared to the gain in downforce $\left(C_{D}=0.03\right.$, $C_{L}=-0.12$ ). Singh and Golsch [12] presented two different angles of a rear-end spoiler proving the effectiveness of this parameter in downforce enhancement.

\section{Underbody Diffusers}

Cooper et al. [13] studied underbody diffusers and highlighted three mechanisms for downforce generation. (I) Upsweep - the inclination of the diffuser resembles that of a wing section and produces downforce by flow deflection. (II) Ground interaction - flow rate increases as the distance between body and ground decreases due to a reduction of the flow cross-section. There is an optimum point for maximum downforce, after which viscosity effects diminishes this gain. (III) Diffuser pumping - an underbody diffuser reduces the pressure behind the car, compared to a baseline case with no diffuser. This is related to the pressure difference between inlet and outlet of this device, creating an increment of flow rate accompanied by an increase in downforce. The final conclusion is that ride height should not be excessively low because all three mechanisms increase drag.

Cooper et al. [14] used a simplified model for experimental studies of high-performance underbody diffusers to show the importance of vehicle geometry. Diffuser length was found to be optimum when nominally half the total length of the underbody, decreasing in magnitude as area ratio (inlet to outlet) is reduced. At the same time, the optimum diffuser length rises as ride height decreases. In a similar study, Zhang et al. [15] found a maximum value of downforce for a given diffuser angle with decreasing ground clearance. A numerical simulation by $\mathrm{Hu}$ et al. [16] of a sedan car demonstrated similar results regarding diffuser performance. An optimum diffuser angle for drag was also found, whereas drag was higher when compared to the baseline case with no diffuser.

Jowsey and Passmore [17] investigated the concept of multiple channels inside a generic underbody diffuser. By comparing 

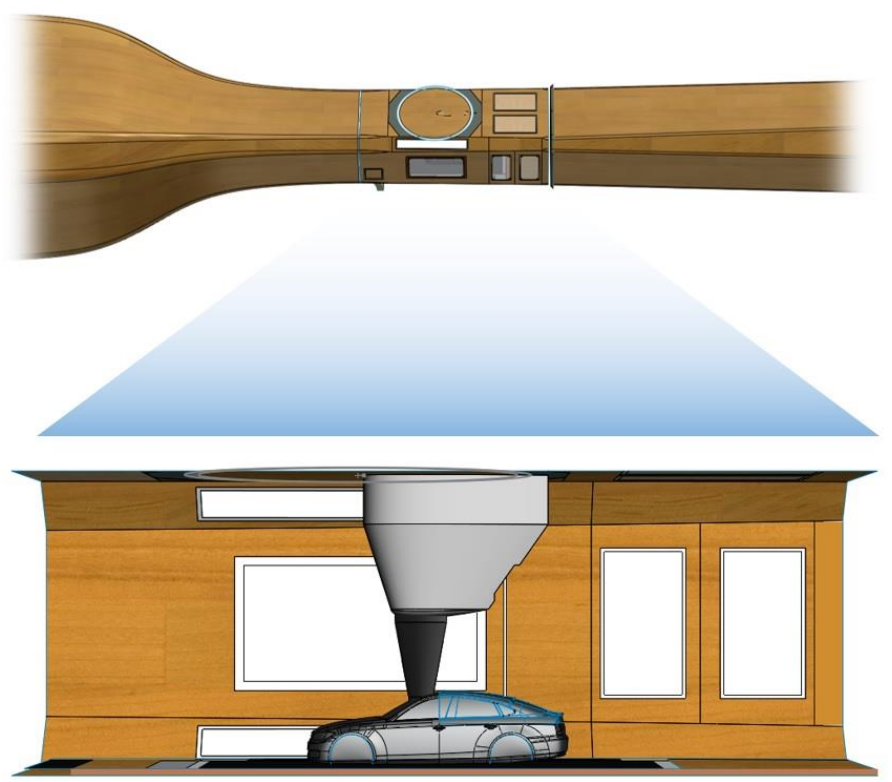

(a)

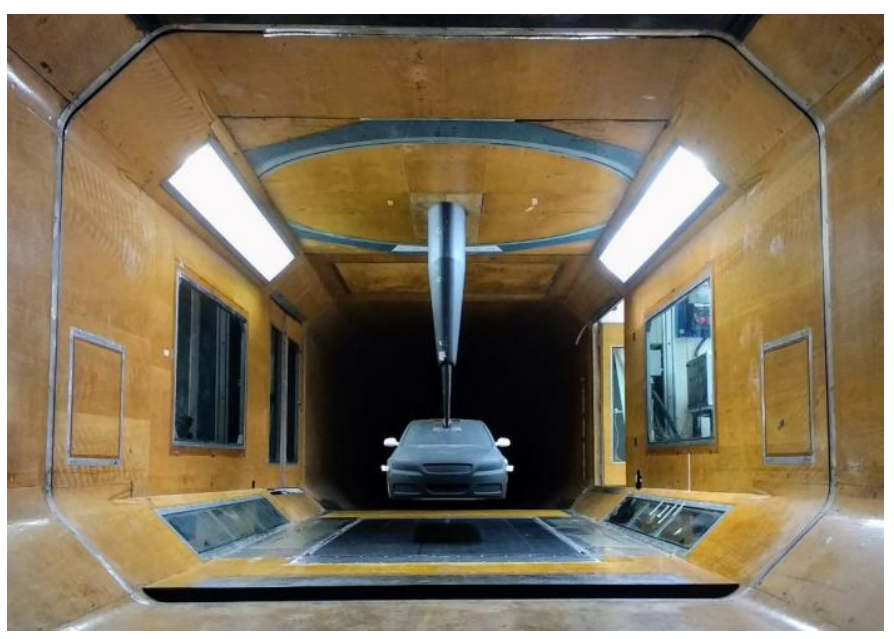

(b)

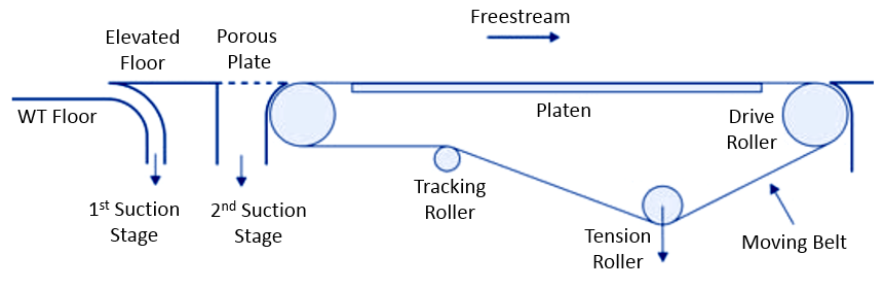

(c)

Figure 2. Illustrations of the experimental facility used: (a) wind tunnel testing section (CAD representation, cutting view); (b) example of experimental case, and (c) sketch of the ground simulation system. experimental values to a channel-free (plain) diffuser, it was seen that an increase of downforce could be achieved at high diffuser angles, compared to the plain diffuser. This enhancement is mainly attributed to a delay in the diffuser stalling angle when multiple channels are used, with a corresponding increase in drag.

A similar concept initiated the longitudinal separators used in the current study. According to Xingjun et al. [18], the mechanism behind these elements is the generation of vortices at the inlet of the diffuser, that become attached to the underbody, generating low-pressure zones with a corresponding increase in downforce. Another benefit is that longitudinal vortices lead to a delay in the diffuser angle at which boundary layer separation occurs, at the expense of additional viscous drag. Their effectiveness in flow control was also proved by Katz and Cain [5]

\section{EXPERIMENTAL METHODOLOGY}

\section{Wind Tunnel Testing Facility}

All tests were carried out in the 8x6 general purpose, closed-return circuit, low-speed wind tunnel at Cranfield University, UK. The facility has a closed rectangular test section $(2.4 \mathrm{~m} \times 1.8 \mathrm{~m})$ with corner fillets and a breather-slot at the downstream end, ahead of the first diffuser (see Figure 2).

In tests for which ground proximity is considered relevant, the basic test section is converted using: (i) a $42 \mathrm{~mm}$ elevated floor, (ii) two stages of upstream boundary layer control, and (iii) a rolling belt system to replicate the relative ground movement. The first boundary layer control stage is a lateral slot intake, while the second stage is a suction system through a porous surface, positioned just upstream of the leading edge of the rolling belt. The exposed rolling belt surface is $1.2 \mathrm{~m}$ wide and $2.75 \mathrm{~m}$ long.

An overhead model mounting strut system - similar to [19][20][21] is adopted, with addition of a 'tail-strut' for model pitch adjustment and remote adjustment of the model ride height. The model is connected to the strut by an internal, 6 component strain gauge balance.

All tests were undertaken at nominally atmospheric pressure and temperature. Both parameters are recorded throughout the test and air density and viscosity calculated assuming Sutherland's Law and the perfect gas relations.

\section{Vehicle Model}

The DrivAer model [19] is the main reference used in this study. The car model has been widely adopted by the research community in automotive aerodynamics as a modern benchmark, and the related CAD files are available on the TUM website [22].

The Cranfield University DrivAer model is a 35\% scale version with two geometric changes, as a result of manufacturing and model mounting constraints, compared to the datum geometry: (i) simplification of the wheel cavities, and (ii) extension of the main underfloor plane surface to the rear axle position (modified smooth underfloor, $\mathrm{S}^{*}$ ). Figure 3 illustrates these modifications, while Table 1 provides the model specifications and Table 2 presents vehicle parametric dimensions used in this paper. 
In this study, the baseline model is the Fastback basic body configuration (FS* ${ }^{*}$ MwoW), which has wheel-related features supressed. The authors decided to use this configuration in order to: (i) assess add-on aerodynamic devices in a progressive degree of complexity (i.e. avoiding effects from the wheels and wheel cavities at this initial stage); (ii) study the effect of ground proximity over wider range of ride heights.

Table 1. Baseline car model specifications.

\begin{tabular}{lcc}
\hline Component & Description & Symbol \\
\hline Rear-end & DrivAer Fastback & $\mathrm{F}$ \\
Underbody & (modified) Smooth underbody & $\mathrm{S}^{*}$ \\
Mirrors & Standard mirrors & wM \\
Wheels & Wheel lid & woW \\
Support Strut & with Top strut & wTS, \\
& with no Wheel struts & woWS \\
\hline
\end{tabular}

Table 2. Parametric dimensions of the DrivAer car model.

\begin{tabular}{lccrc}
\hline Parameter & Symbol & Definition & Value & \\
\hline Car scale & $C S$ & - & $35 \%$ & - \\
Reference length & $L$ & $4.6126 C S$ & 1.6144 & $m$ \\
Reference ride height ${ }^{\dagger}$ & $h_{o}$ & $0.130 C S$ & 0.0455 & $m$ \\
Foremost x-position & $x / L=0$ & $-0.8075 C S$ & {$[-0.2826,0,0]$} & $m$ \\
Front wheels axle position & $x_{F}$ & - & {$[0,0,0]$} & $m$ \\
Rear wheels axle position & $x_{R}$ & $2.7862 C S$ & {$[0.9752,0,0]$} & $m$ \\
Reference width; & $W$ & $1.7529 C S$ & 0.7012 & $m$ \\
Wheeltrack & $W B$ & $2.7862 C S$ & 0.9752 & $m$ \\
Wheelbase & $A_{\text {ref }}$ & $2.0868 C S^{2}$ & 0.2556 & $m^{2}$ \\
Reference area & (FSwMwoW) & 0.255 & \\
\hline
\end{tabular}

${ }^{\dagger}$ The ground plane is not defined on the original DrivAer CAD pack. This parameter is estimated by placing a plane tangential to the wheel surfaces, with an assumption of tyre deformation of $\delta \mathrm{t}=0.022 \mathrm{CS}[\mathrm{m}]$ (see Figure 4). Additional comments related to ground plane reference and tyre patch for DrivAer model are available at [23] and [24].

Table 3. Parametric description of the add-ons tested.

\begin{tabular}{|c|c|c|c|}
\hline Parameter & Levels & Value & Unit \\
\hline \multicolumn{4}{|l|}{ Spoiler } \\
\hline Size & 3 & {$[40,80,120]$} & $\mathrm{mm}$ \\
\hline Angle & 3 & {$[20,40,60]$} & deg \\
\hline \multicolumn{4}{|l|}{ Diffuser } \\
\hline Angle & 4 & {$[0,5,10,16]$} & deg \\
\hline Longitudinal separators & 2 & {$[O F F, O N]$} & - \\
\hline \multicolumn{4}{|l|}{ Splitter } \\
\hline Size & 6 & {$[6,12,18,30,35,41]$} & $\mathrm{mm}$ \\
\hline \multicolumn{4}{|l|}{ Strakes } \\
\hline Size & 3 & [Small, Medium, Large] & - \\
\hline Assembly set & 3 & [Lower-set, Upper-set, Full-set] & - \\
\hline
\end{tabular}

Page 4 of 27

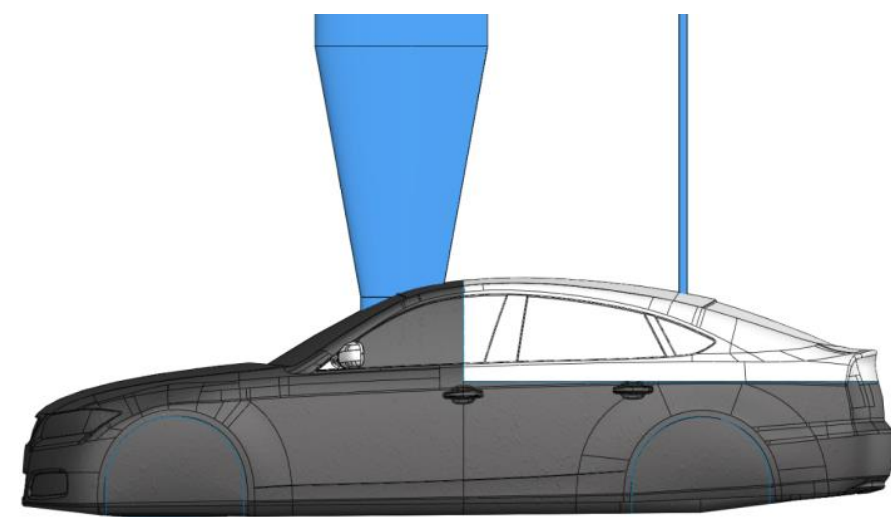

(a)
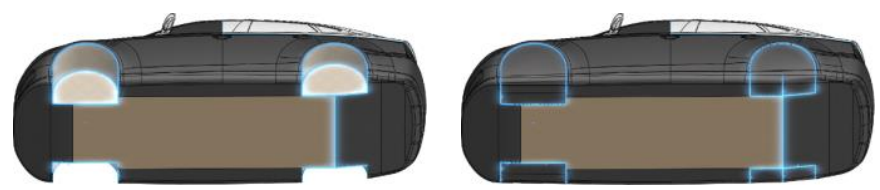

(b)

Figure 3. CAD sample of the Cranfield modified version of the DrivAer body with smooth underfloor: (a) baseline car case as experimentally tested (FS ${ }^{*}$ wMwoW, GS on, wTS), (b) highlight on the modified edges: extension of the main underfloor surface, wheel cavities (wW) and wheel lids (woW).

Model ride height $(h)$ is defined as the minimum distance between the reference ground plane and the lowest underfloor point (see Figure 4), also known as 'gap clearance'. This work refers to this parameter in its normalised format $\left(h / h_{0}\right)$, where $h_{0}$ is the standard ride height measured on the DrivAer car model with smooth underfloor. The lowest point on this model is situated just forward of the front axle position.

\section{Aerodynamic add-on components}

Among the large diversity of aerodynamic components employed in motorsport, and specifically in enclosed-wheel race car categories, four generic aerodynamic devices have been selected for parametric assessment. These are: (i) forebody strakes, (ii) a front splitter, (iii) a rear-mounted spoiler, and (iv) an underbody diffuser.

The simplified design of these add-on devices focuses on key parameters (such as length, position, or angle of incidence). This simplified geometry in each case was specifically to: (i) provide an easier manufacturing process for experimental sub-scale models and (ii) aid implementation within the grid topology for computational studies. Table 3 outlines the key geometric characteristics of each addon component considered.

\section{Test Procedure}

All measurements, during this initial assessment phase, were made at zero-yaw. The original version of the DrivAer smooth underfloor vehicle is composed of multiple surfaces at various angles to the ground plane. As a result, the horizontal rear-end cutting edge, which is parallel to coordinate system (and consequently assumed to be parallel to any ground surface), is used to set the model at the standard pitch incidence. This was considered to adequately match the positioning characteristics of the standard DrivAer CAD geometry and its related technical literature. 


\section{Data Acquisition and References}

Aerodynamic forces and moments acting on the model are measured using an Aerotech $^{\circledR}$ six-component internal balance. The manufacturer's calibration gives the maximum measurement uncertainty as $\pm 0.06 \%$ of full-scale value for each force component, corresponding to $\pm 0.90 \mathrm{~N}$ for lift and $\pm 0.18 \mathrm{~N}$ for drag [25]

During each test run, force and moment data was recorded at several model ride heights, the test sequence always starting from the highest position $\left(h / h_{0}=2.00\right)$ and ending at the minimum $\left(h / h_{0}=0.20\right)$. For each ride height of interest, the vertical translation of the model had been ceased such that the model was stationary for at least 10 seconds prior to data acquisition.

The wind tunnel speed during the test (for both freestream and moving ground) showed fluctuations that can be regarded to be $\pm 0.1 \mathrm{~m} / \mathrm{s}$ in most of the cases.

The conventional non-dimensional coefficients for drag and lift are adopted in this work as:

$$
C_{i}=\frac{F_{i}}{\frac{1}{2} \rho_{r e f} U_{r e f}^{2} A_{r e f}} ; i=\left[D, L, L_{f}, L_{r}\right]
$$

Note also that automotive aerodynamics consider 1 count as a millesimal unit of force coefficients $\left(\Delta C_{i}=0.001\right)$, in constraints to usual convention in aeronautical aerodynamics.

An indicator of aerodynamic efficiency adopts the aeronautical convention of "lift to drag ratio" $(L / D)$ with a sign change to reflect that a negative lift or downforce is a positive attribute in this case:

$$
A E=\frac{(\text { downforce })}{(\text { drag })}=-\frac{L}{D}
$$

Aerodynamic balance is defined in this paper as the ratio between the intensity of downforce loaded on the front axle position in relation to the total (or net) downforce over the vehicle:

$$
A B_{\% f}=\frac{C_{L f}}{C_{L}} \times 100[\%]
$$

Please note that $A B$ assess the vertical loads only. It can be used as a parameter to estimate under- or over-steering behaviour due to downforce generation (mainly relevant on higher speed). This term may differ to the centre of pressure, where drag and side forces must be considered. For more information, the work of Howell and Le Good [26] is recommended whenever driving stability is concerned.

The collection of experimental results presented in this paper does not include any correction factor. The experiments were done under a wind tunnel blockage of $\approx 10.2 \%$, considering that the empty working cross-section has $4.2075 \mathrm{~m}^{2}$ and the car model and top strut has a total frontal area of $\approx 0.4272 \mathrm{~m}^{2}$. Uncorrected blocking factor results were chosen in order to not mislead interpretation of research colleagues due to different variations of blockage correctors. Additionally, this uncorrected experimental data can be easier used for CFD validation purpose, as the same nominal freestream and air properties can directly applied in cases whenever the experimental domain is replicated (i.e. fundamental concept in CFD validation procedure: replication of experimental conditions and constraints under minimal uncertainty).

\section{DISCUSSION OF EXPERIMENTAL RESULTS}

The subsequent sub-sections aim to describe the characteristics of aerodynamic loading in relation to:

(a) the baseline car body (i.e. DrivAer Fastback, FS*wMwoW).

(b) an individual and parametric assessment of the four chosen aerodynamic devices: (i) forebody strakes, (ii) front bumper splitter, (iii) rear-end spoiler, and (iv) underbody diffuser.

(c) the proposed high-performance DrivAer Fastback configuration (i.e. hp-FS* wMwoW)

All experimental results are presented in graph format at the Appendix only (Figure 10 to Figure 18), due to the large amont of data (i.e. DOE involving over a hundread cases). For a better reading of this discussion section, it is recommended to take that entire section apart for a simultaneous assessment. Dataset in spreadsheet format is available at CORD [27].

\section{Aerodynamic Characteristics of the Baseline Case: $F S^{*} w M w o W, G S$ on}

\section{Ride height sensitivity of aerodynamic loads}

All tests had been initiated from $h / h_{0}=2.00$ (i.e. maximum gap, $91 \mathrm{~mm}$ ) towards to $h / h_{0}=0.20$ (i.e. minimum gap, $9.1 \mathrm{~mm}$ ), which are illustrated in Figure 4. As the car model approaches the rolling belt, the results are in broadly consistent with the changes generally expected for vehicles in 'ground effect'.

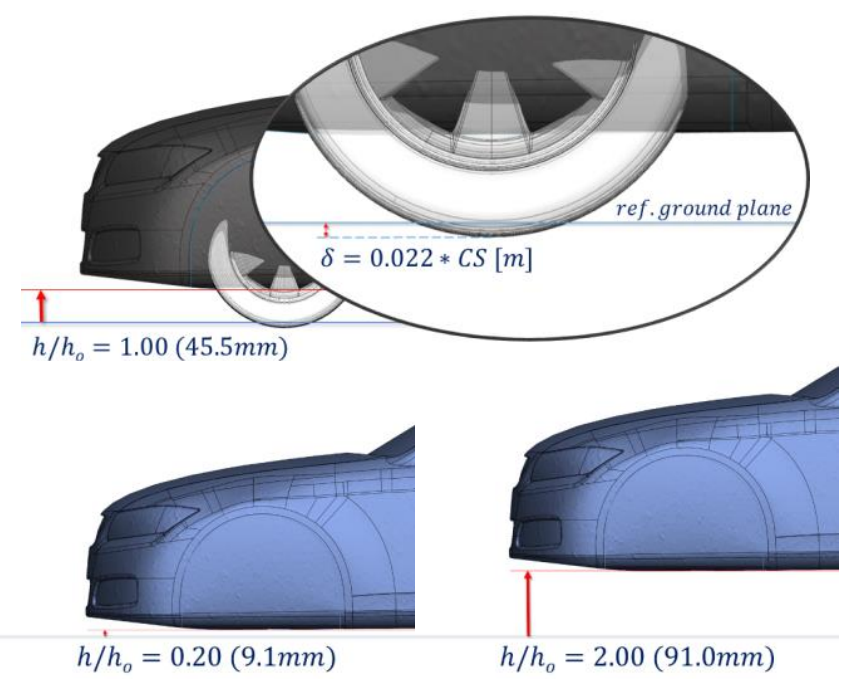

Figure 4. Ride height: illustration of the normalised unit and the minimum and testing limits. Inset shows the definition of the ground reference level. 
The minimum and maximum values of drag coefficient were found at $h / h_{0}=2.00$ and 0.33 , respectively. Although drag sensitivity is less significant (e.g. $\left.\max \left[\Delta C_{D} / C_{D(h=2.0)}\right] \approx 3.4 \%\right)$, this evidence suggests that the influence of ground proximity occurs in two stages. From $h / h_{0}=2.00$ to 0.33 , drag growth increases in an exponential trend as ground clearance decreases, until reach the maximum drag $\left(C_{D}=0.168\right)$. Drag reduces by 2 counts $\left(\Delta C_{D}=0.002\right)$ at $h / h_{0}=$ 0.25 and increases anew at $h / h_{0}=0.20$, respectively. Unfortunately, a statistical study on this baseline case indicated that drag values have a confidence interval of nearly $\Delta C_{D}=0.004$, which means that these fluctuations are not statistically significant due to the magnitude of experimental uncertainty.

By contrast to drag, downforce shows considerable sensitivity to ride height changes. Minimum and maximum downforce were found at $h / h_{0}=2.00$ and 0.50 , respectively. After displacing the model from $h / h_{0}=2.00$ to 0.50 , downforce increases gradually to 2.7 times and reaches the maximum plateau found in the range of $0.25 \leq h / h_{0} \leq$ 0.50 . The last height range $\left(h / h_{0}<0.25\right)$ suggests the beginning of a sharp downforce decay, as $C_{L(h=0.2)} / C_{L(h=2.0)}=2.49$.

Aerodynamic efficiency characteristics are mostly dominated by downforce changes as the drag sensitivity is low. Minimum aerodynamic efficiency was measured at the highest position, where drag and downforce are at equivalent magnitudes $(A E=1.01)$. Aerodynamic efficiency increases in an smooth, positive parabolic curve up as ride height decreases to $h / h_{0}=0.50$. The ride height range between $0.25 \leq h / h_{0} \leq 0.50$ provides a plateau of maximum efficiency of approximately 2.7. The following height, $h / h_{0}=0.20$, indicates a sharp loss in comparison to the maximum plateau.

\section{Aerodynamic Characteristics of each Add-on Components on the Baseline Car Model}

\section{Front Bumper Splitter}

The splitter was a flat plate (rectangular, with rounded leading edge corners) designed to vary with length, attached to the bottom of the front bumper. The simplified design resulted in an unusual incidence angle (positive, see Figure 5b), however the findings can give the opportunity to compare the impact of incidence angle when compared to the published, zero-pitch angle studies. The splitter size is defined as the protruding distance from the centre point situated at the lowest bumper edge. Different sizes can be represented by sliding the plate and fixing it with a set of 4 bolts. Six splitter sizes were successfully tested: $6 \mathrm{~mm}, 12 \mathrm{~mm}, 18 \mathrm{~mm}, 30 \mathrm{~mm}, 35 \mathrm{~mm}$ and $41 \mathrm{~mm}$. Figure 5 illustrates this device in $\mathrm{CAD}$ and in experimental test.

The largest splitter produces less drag than the smallest splitter, but still more drag than the baseline. However, all splitter sizes indicate a similar variation of drag coefficient with ride height, typically in the range, between minimum $(6 \mathrm{~mm})$ and maximum $(41 \mathrm{~mm})$, of no more than $\Delta C_{D}=0.006$ (see data in Figure 10). At the minimum ground clearance, $h / h_{0}=0.20$, the drag coefficient for these devices is nominally the same as for the baseline case $\left(C_{D}=0.166\right)$, while the insertion of splitter at the maximum ride height, $h / h_{0}=2.00$, generates an increment of at least $\Delta C_{D}=0.010$.

The sensitivity of downforce to splitter size is small, particularly when compared to the influence of ride height. In terms of the downforce distribution (front to rear), it is evidenced that longer splitters produce
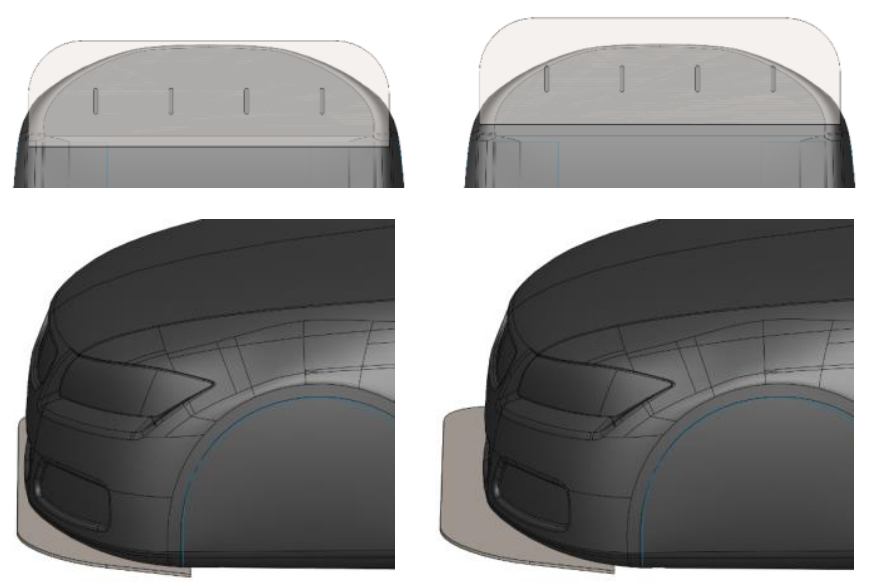

(a)

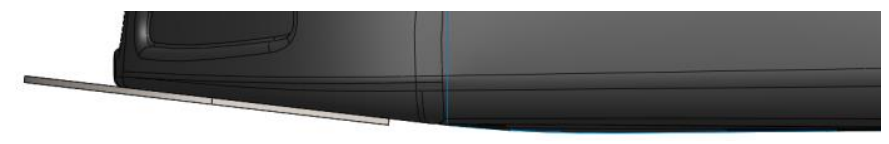

(b)

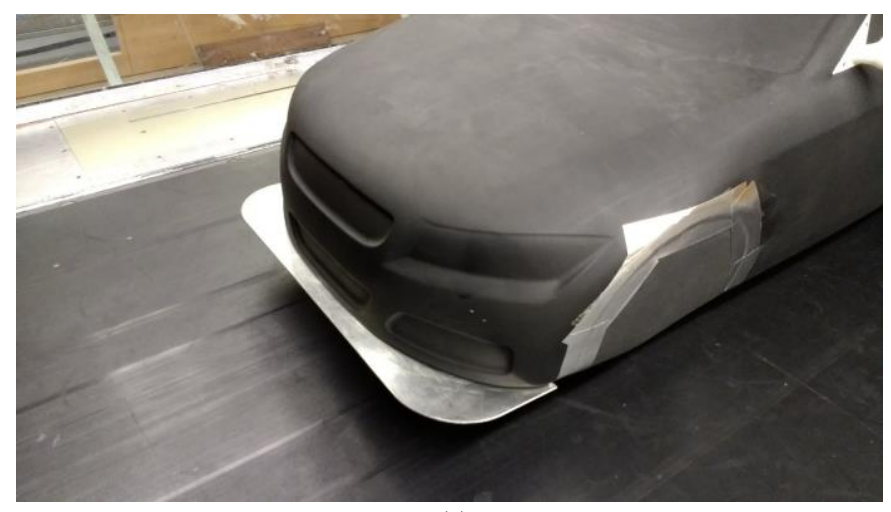

(c)

Figure 5. Front bumper splitter: (a) CAD illustration of the minimum ( $6 \mathrm{~mm}$, at right) and maximum (41 $\mathrm{mm}$, at left) splitter length; (b) inherent angle of incidence; (c) sample of experimental case tested $(41 \mathrm{~mm})$.

more front downforce, but small splitters provide more rear downforce. This is consistent with the findings presented by Singh [4].

The effect of a splitter on downforce is smaller than expected. This is assumed to be due to the simplistic mounting of the splitter (see Figure 5b). A preferable mounting would be with the splitter plate parallel to the ground plane.

An assessment of measurement repeatability was made for the $35 \mathrm{~mm}$ splitter case. This data is reflected in the charts shown in Figure 6 and represents a precision of $\Delta C_{D}= \pm 0.002$ (e.i. $>1 \%$ of the magnitudes acquired in this testing group). 


\section{Forebody Lateral Strakes}

Two pairs of strake roots were designed in order to match the model forebody curvature. These were (i) lower position, and lower angle of incidence, and (ii) upper position and higher incidence angle. Each base root had been extruded in three different strake sizes (see Figure $6 b)$. Stakes were manufactured using a $3 \mathrm{D}$ polymer printer.

The strakes are categorised in terms of size as small, medium, or large; and in terms of position as lower-set, upper-set, or both (hereafter referenced as full-set). Figure 6 exemplifies these categories.

\section{Forebody Lateral Strakes: influence of size}

In this subtopic we consider a full-set of strakes (four strakes simultaneously) assessed as a function of size. The data is presented in Figure 11.

The general trend is for drag coefficient to increase as the strakes size increases. All strake sizes show a peak drag coefficient at $h / h_{0}=$ 0.33 , as for the baseline. The biggest differences occur at low ride heights.

Gains in total downforce is not at the same ratio as drag. Small-size strakes curve shows gain in downforce around 100 counts along the most range of the ride height. No significant gain is achieved by increasing the strake to medium- or even to large-size. The offset gain is reduced in close proximity to the ground, analogously to the height range of drag reduction. It gives evidence that both drag and downforce reductions are strongly connected and would be under the effect of a same aerodynamic mechanism.

The front axle is more susceptive to downforce changes due to the strakes position at forebody region. The increasing the downforce at the rear axle is not as expected, even though at a minor magnitude: 40 counts, on average.

In terms of downforce, increasing strake size from small to large, has little effect, and the sensitivity to ride height is similar to that seen for the baseline configuration. As expected, the strakes have a bigger influence on front axle downforce. However there is also a downforce increment $\left(\Delta C_{L}=-0.040\right)$ at the rear axle

\section{Forebody Lateral Strakes: influence of assembly set}

In this section the effect of strake combination (lower, upper, and both) is considered for the large strakes only, the data is presented in Figure 12.

In general, the upper strakes in isolation produce more downforce than the lower strakes. Both are more effective at lower ride heights. Clearly there is an interference effect as when both upper and lower strakes are used the incremental effect is small.

Analysis of the drag coefficient data suggests a similar response to that seen for downforce. The drag penalty of the full-set of strakes is seen to be similar to that for the upper set in isolation. In applications where a high-downforce configuration is required and/or there is a need to move the aerodynamic balance forwards, the full-set of strakes provides a more effective solution when compared to the upper set in isolation.

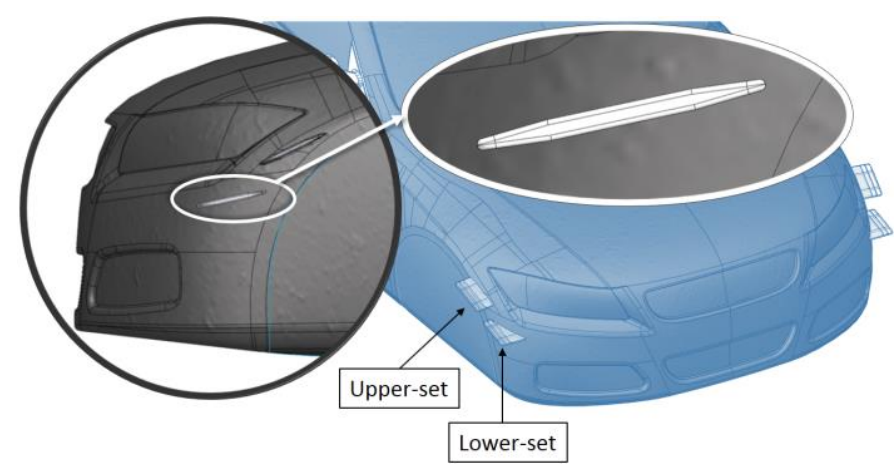

(a)

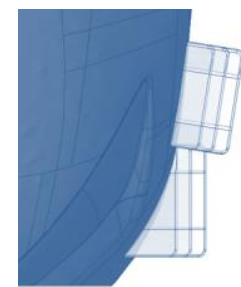

(b)

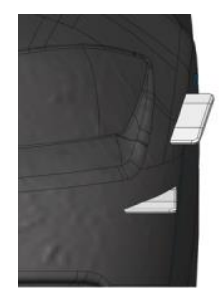

(e)

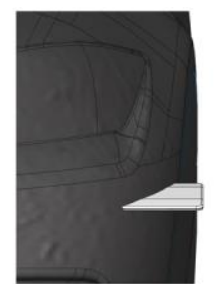

(c)

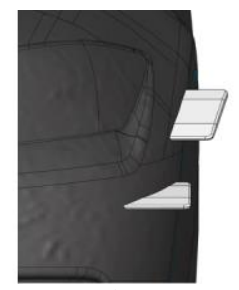

(f)

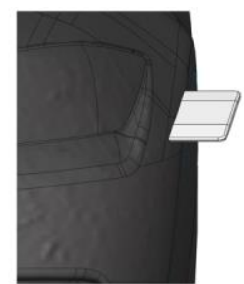

(d)

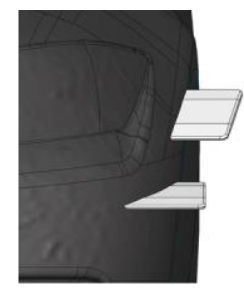

$(\mathrm{g})$
Figure 6. Forebody lateral strakes. CAD illustration of (a) incidence angle and general profile, and (b) strake extrusion; front view of (c) lower- and (d) upperset of strakes (in large-size); (e) small-, (f) medium-, and (g) large-size (in fullsets). Pictures in blue show overlapped strakes for comparison purpose.

In cases where high-downforce configuration are required and/or there is a need of moving aerodynamic balance forwards, the full-set provides a useful outcome: additional 20 downforce count on the front axle, when comparing to the upper-set performance only.

All strakes configuration are under a severe downforce reduction after $h / h_{0}=0.33$, as also seen when analysing strake sizes.

\section{Rear-end Spoiler}

The simplified spoiler set has two parameters: (i) length ( $s p L)$ and (ii) angle of incidence $(s p A)$. The effect of spoiler length had been studied by using rectangular, flat, aluminium plates, of three sizes: $40 \mathrm{~mm}$, $80 \mathrm{~mm}$, and $120 \mathrm{~mm}$. Changes in angle of spoiler incidence is achieved by the use of simple block supports with angles of 20,40 and 60 degrees. Figure 7 illustrates (a) angle of incidence, (b) size, and (c) installation of a spoiler for experimental testing.

In order to assess the influence of spoiler incidence angle, spoilers of $s p L=80 \mathrm{~mm}$ were used. While cases of $s p A=40 \mathrm{deg}$ would highlight the influence of spoiler size on aerodynamic loads. 

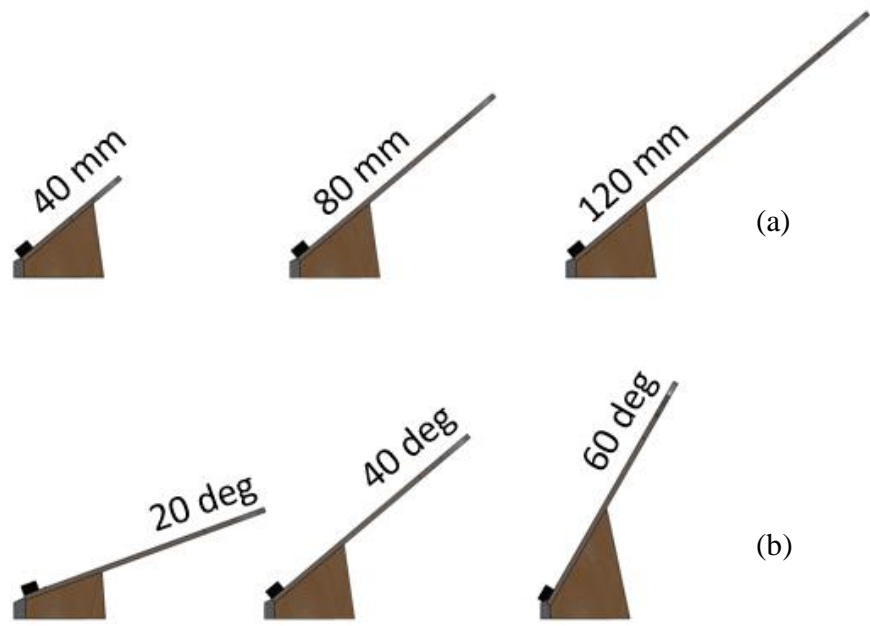

(b)

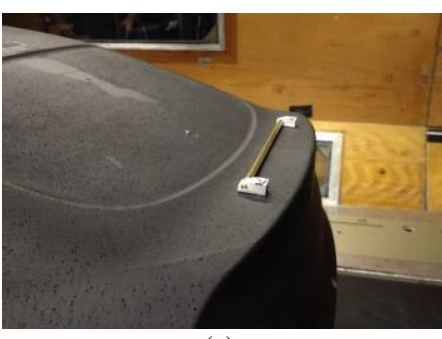

(c)

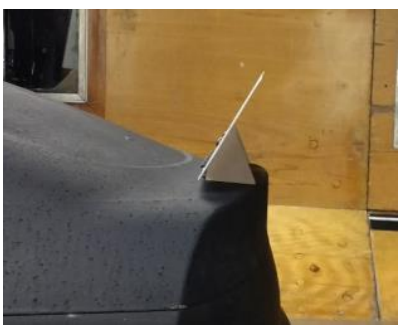

(d)

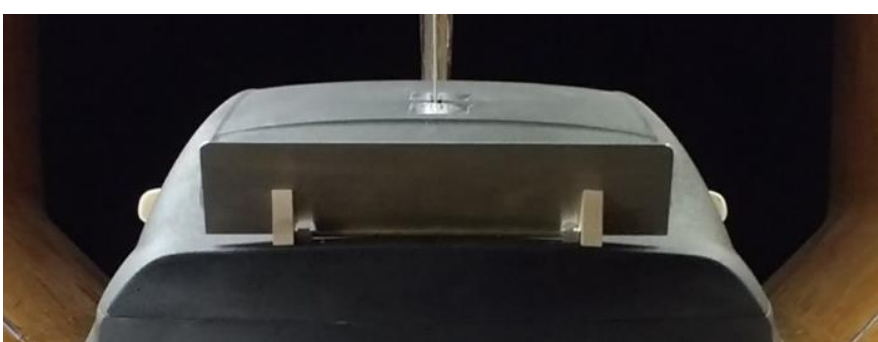

(e)

Figure 7. Rear-end Spoiler. CAD illustration of (a) size and (b) angles of incidence; (c) common spoiler mounting; (d) fitting a spoiler plate and block supports; (e) sample of an spoiler case ready for experimental test.

\section{Rear-end Spoiler: influence of angle of incidence}

The results, presented in Figure 13, suggest that there is an optimum angle for downforce increment, where any additional angle of incidence will result in a loss of aerodynamic efficiency. Overall downforce is substantially increased when a spoiler is fitted, even at a lower angle of spoiler incidence.

For all angles of spoiler incidence, the variation of downforce with ride height is similar to that seen in the baseline case. However, spoiler configurations are more sensitive to ride height changes as the optimum ride height is approached near to the ground. When compared to the baseline, at $h / h_{0}=2.00$, the total downforce is nearly twice for spoiler angles of $20 \mathrm{deg}, 2.3$ times for $40 \mathrm{deg}$, and 2.4 times for $60 \mathrm{deg}$. At maximum downforce ride height, the downforce ratio for $\operatorname{spA}=20,40$, and $60 \mathrm{deg}$ are 1.61, 1.89, and 1.95 , respectively.

For all angles of incidence, the behaviour of the total downforce curve resembles the baseline body case, however, the maximum plateau range $\left(0.25<h / h_{0}<0.50\right)$ is converted to a single point found at $h / h_{0}=0.25$ : a result from the transformation of a positive to a negative parabolic curve as the vehicle moves towards to the ground. On the other hand, the magnitude is the main difference between them. Comparing to the baseline, at $h / h_{0}=2.00$, the total downforce is nearly twice for $20 \mathrm{deg}, 2.3$ times for $40 \mathrm{deg}$, and 2.4 times for $60 \mathrm{deg}$. At maximum peak, the downforce ratio for $s p A=20,40$, and $60 \mathrm{deg}$ are $1.61,1.89$, and 1.95 , respectively.

As expected, the rear downforce increases with increasing spoiler angle. However, the front axle downforce is also affected by rear spoiler angle and shows similar proportional increments, but in the opposite sense. Rear downforce ratio of 0.94 for $20 \mathrm{deg}, 0.91$ for $40 \mathrm{deg}$, and 0.89 for $60 \mathrm{deg}$, all compared at $h / h_{0}=0.33$ against the baseline magnitude.

There is a corresponding increase in drag coefficient with spoiler angle which is seen to be related to the downforce.

The performance similarity between spoilers with angle of incidence of $40 \mathrm{deg}$ and $60 \mathrm{deg}$ is not only evident on total downforce but also on its distribution, as they do not differ more than 30 downforce counts $\left(\Delta C_{L} / C_{L\left(40^{\circ}\right)}=3.5 \%\right)$ at the peak. For drag, there is an increase of 26 drag counts at the same ride height $\left(\Delta C_{D} / C_{D\left(40^{\circ}\right)}=8.2 \%\right)$.

The performance similarity between spoilers with angles of incidence of $40 \mathrm{deg}$ and $60 \mathrm{deg}$ is not only evident on total downforce but also on front-rear distribution.

\section{Rear-end Spoiler: influence of size}

Figure 14 display the experimental results of the influence of spoiler size on the aerodynamic characteristics of the model.

Total downforce coefficient shows substantial improvement even with the smallest spoiler $(40 \mathrm{~mm})$. The downforce increment from the baseline case at $h / h_{0}=2.00$ is nominally $\Delta C_{L}=-0.2$, of which $\sim 10 \%$ is on the front axle and $\sim 90 \%$ at the rear. The downforce coefficient peak is found at $h / h_{0}=0.25$, and is the same for all spoiler sizes.

The significant downforce increments are reflected in a large penalty in terms of drag coefficient. The maximum drag coefficient of 0.230 , 0.318 , and 0.415 are measured for $s p L=40,80$, and $120 \mathrm{~mm}$, respectively.

In terms of downforce distribution, the data show that as the spoiler size increases, the strong increase in rear axle downforce is accompanied by a reduction in the front axle load. The extreme case $(s p L=120 \mathrm{~mm})$ would move the aerodynamic balance to $30 \%$, highlighting the effectiveness of this type of device for producing rear axle downforce. 


\section{Underbody Diffuser}

The design of the underfloor diffuser required a modification to the original model which involved the removal of material between the rear wheel cavities (see Figure 8a). This new cavity housed the adjustable rear diffuser plate.

Four inserts were manufactured in order to fill the void between the diffuser plate and the main model body corresponding to diffuser angles of $0 \mathrm{deg}$ (i.e. no-slant surface), $5 \mathrm{deg}, 10 \mathrm{deg}$, and $16 \mathrm{deg}$. Note that the baseline model has a rear underbody angle equivalent to a diffuser of approximately $7 \mathrm{deg}$. It means that the 0 and $5 \mathrm{deg}$ diffuser cases are protruding below the model. Aluminium side plates are included in the diffuser configuration in order to cover the lateral opening from the cavity cutting, as well to allowing investigation of those four angles in a comparable configuration.

\section{Underbody Diffuser: influence of angle of incidence}

The aerodynamic data (see Figure 15) suggest that the model is in the influence of the ground plane at the highest ride heights tested for all diffuser cases.

The case of $\operatorname{diffA}=0 \mathrm{deg}$ illustrates what would be the characteristics of the DrivAer configuration if it had no sloping surface in the underfloor. Downforce is reduced, compared to the DrivAer baseline, for all ride heights tested, which is primarily attributed to a loss of downforce at the rear axle.

Even the smallest diffuser angle tested ( $\operatorname{diff} A=5 \mathrm{deg}$ ) highlights the impact of an underbody diffuser, when compared to the 'no-diffuser' case ( $\operatorname{diff} A=0 \mathrm{deg})$. Although no significant variation is seen at the front axle, rear axle loading is significantly different and maximum net downforce is more than doubled $(\times 2.15)$ while drag is reduced for all ride heights tested.

Total downforce increases as diffuser angle increases, up to $\operatorname{diff} A=$ $10 \mathrm{deg}$, above which there is a loss in downforce. The incremental change is greatest at the smaller differ angles.

For the case of $\operatorname{diffA}=16 \mathrm{deg}$, the rear downforce data show that this configuration has the best performance at higher model ride heights. However, as the model approaches the ground, the rear axle loading is progressively reduced until $h / h_{0}=0.33$, where a sharp loss occurs. The front downforce variation is also influenced and becomes less effective than the $\operatorname{diff} A=10 \mathrm{deg}$ case for $h / h_{0}<1.00$.

In terms of the overall loading, the $\operatorname{diff} A=10 \mathrm{deg}$ case provides the best aerodynamic efficiency, with a peak $(A E=3.05)$ at $h / h_{0}=0.25$. Note that the baseline case tested has an underfloor slant angle of $7.1 \mathrm{deg}$, and even without the side plates, it performance was similar to what would be a diffuser case of $\operatorname{diff} A \approx 7 \operatorname{deg}$ in this study.

A repeatability analysis of data for the underbody diffuser tests (based on the $\operatorname{diff} A=10 \mathrm{deg}$ case) shows that the drag and downforce coefficient data have a confidence interval of $4 \%( \pm 2 \%$ from the mean value) for higher positions $\left(h / h_{0} \geq 1.00\right)$. This is attributed to the onset of unsteady flow when the diffuser angle is $\operatorname{diff} A=10 \mathrm{deg}$. This has no impact on the overall conclusions that can be drawn from the data as the incremental changes seen are greater than the uncertainty.

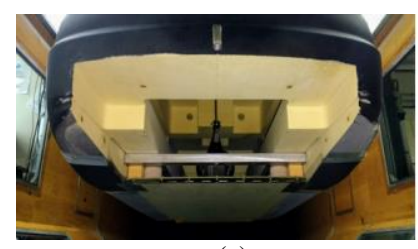

(a)
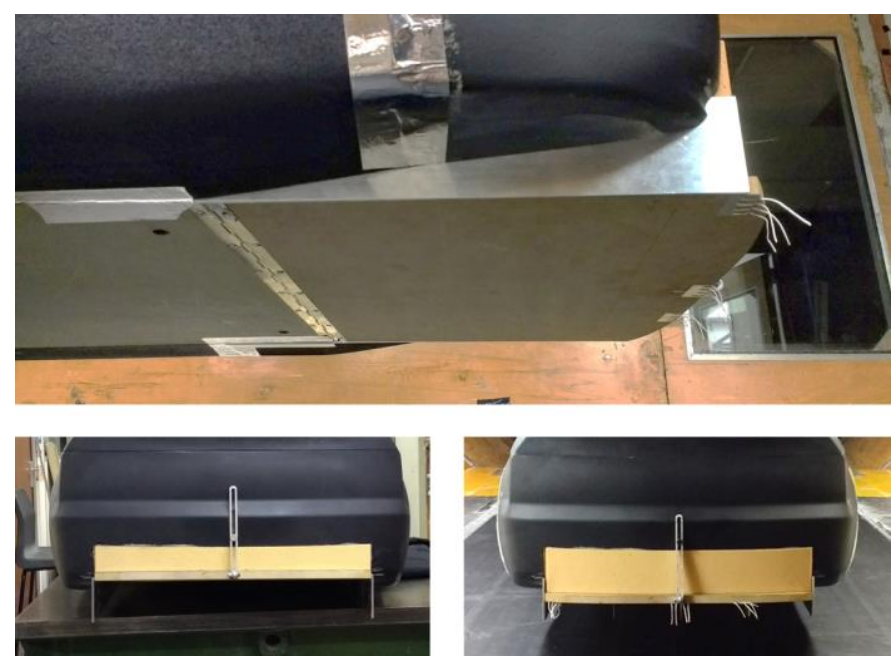

(c)

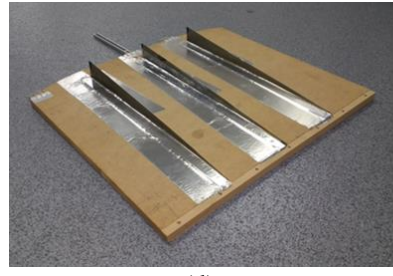

(d)

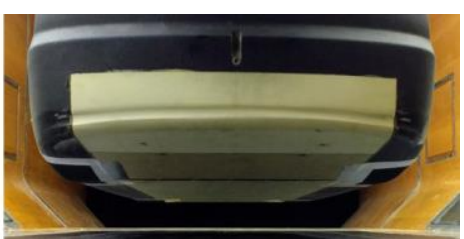

(b)

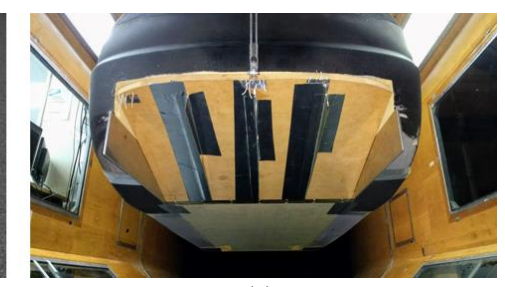

(e)

Figure 8. Underfloor diffuser: (a) diffuser cavity; (b) baseline insert; (c) flat diffuser cases of $0 \mathrm{deg}, 5 \mathrm{deg}$, and $10 \mathrm{deg}$ (top, clockwise); (d) diffuser board surface with longitudinal separators and installation as (e) 16 deg case (SEP on).

\section{Underbody Diffuser: influence of longitudinal separators}

When the optimum diffuser angle, $\operatorname{diff} A=10 \mathrm{deg}$, was identified, the effectiveness of longitudinal separators was assessed. Three Lshaped, metallic strips were manufactured with a longitudinal angle of $5 \mathrm{deg}$, with leading edges positioned at the diffuser board hinge and spaced equidistantly $100 \mathrm{~mm}$ apart.

As seen in Figure 16, net downforce was reduced in an offset-trend in almost all ride heights tested, except at $h / h_{0}=0.75$. The main contribution for this overall reduction is seen in the front axle loading, nominally $\Delta C_{L} \sim 0.03$ for most ride heights, while changes in the rear downforce is more complex.

The incremental drag coefficient data is seen to be statistically insignificant for most of the ride heights, with exception of an additional drag penalty of 3,5 and 4 drag counts for $h / h_{0}=0.25$, 0.50 , and 0.75 , respectively. 
The performance of the longitudinal separator was not as expected for $\operatorname{diff} A=10 \mathrm{deg}$, primarily responsible for introducing an aerodynamic mechanism that reduced the front axle downforce. However, aerodynamic balance was improved for lower ride heights $\left(h / h_{0}<1.00\right)$, such as $A E=68 \%$ for $h / h_{0}=0.25$ and as $A E=$ $66 \%$ for $h / h_{0}=0.75$.

Two additional cases were tested: $5 \mathrm{deg}$ and $16 \mathrm{deg}$. The first shows a small increment of downforce and their effect is virtually independent of ride height. This is accompanied by an increase in drag. When the diffuser angle is set to $16 \mathrm{deg}$, a considerable downforce gain is only observed at $h / h_{0}=0.75$. This finding exemplifies the potential flow control when applied on 'plain' diffuser design; boosting downforce gains to a lower ride height range, whereas with a corresponding penalty in drag in some cases.

The results show that the aerodynamic performance can be complex when considering longitudinal separators, as diffuser vortices breakdown appears to be delayed and/or mitigated at specific ride height conditions.

\section{Aerodynamic Characteristics of the Proposed High- performance Configuration: $h p-F S^{*} w M w o W, G S$ on}

Based on the discrete assessment of each aerodynamic device, the final stage of the experimental programme was performed with the proposed high-performance DrivAer Fastback configuration, hereafter named DrivAer hp-F (Figure 9). This car configuration is based on the DrivAer Fastback (Table 1), and the term ' $h p$-' detonates the highperformance kit summarised in Table 4.

Table 4. DrivAer High-performance Fastback: add-on specifications.

\begin{tabular}{cc}
\hline \multicolumn{2}{c}{ Forebody Add-ons } \\
\hline Splitter & Strakes \\
\hline $41 \mathrm{~mm}$ & $\begin{array}{c}\text { Full-set; } \\
\text { Large-size }\end{array}$ \\
\hline
\end{tabular}

\begin{tabular}{cc}
\hline \multicolumn{2}{c}{ Rear body add-ons } \\
\hline Spoiler & Diffuser \\
\hline $80 \mathrm{~mm} ;$ & $10 \mathrm{deg} ;$ \\
$40 \mathrm{deg}$ & SEP on \\
\hline
\end{tabular}

\section{Ride height sensitivity of aerodynamic loads}

The high-performance configuration is compared to the baseline car at the same eight ride heights, from $h / h_{0}=2.00$ to 0.20 , in order to quantify the gains in performance. The experimental data is presented in Figure 17.

Net downforce coefficient is substantial even furthermost from the ground. $C_{L}=-0.60$ for the DrivAer $h p-F$ compared to $C_{L}=-0.16$ produced on the baseline model. Downforce progressively increases as the ride height decreases until the downforce peak $\left(h / h_{0}=0.33, C_{L}=\right.$ $-1.09)$. Any further ride height reduction will also reduce downforce. Even though net downforce have higher proportions in comparison to the baseline, both present the same downforce decay $\left(\Delta C_{L}=0.036\right.$ for $\left.h / h_{0}=0.25 \rightarrow 0.20\right)$. The high performance configuration is less sensitive to ride height between $0.25 \leq h / h_{0} \leq 0.50$; a range of ride height that generate $C_{L}>1.00$. This broader optimum range rather than a peak has beneficial characteristic for motorsport applications.

Both front and rear downforce components are improved in a similar trend to the net downforce. The maximum front downforce is $0.33 \leq$ $h / h_{0} \leq 0.50$, while the downforce peak was more evident at the rear component $\left(h / h_{0}=0.33 ; C_{L r}=-0.630\right)$. It becomes clear that the

Page 10 of 27
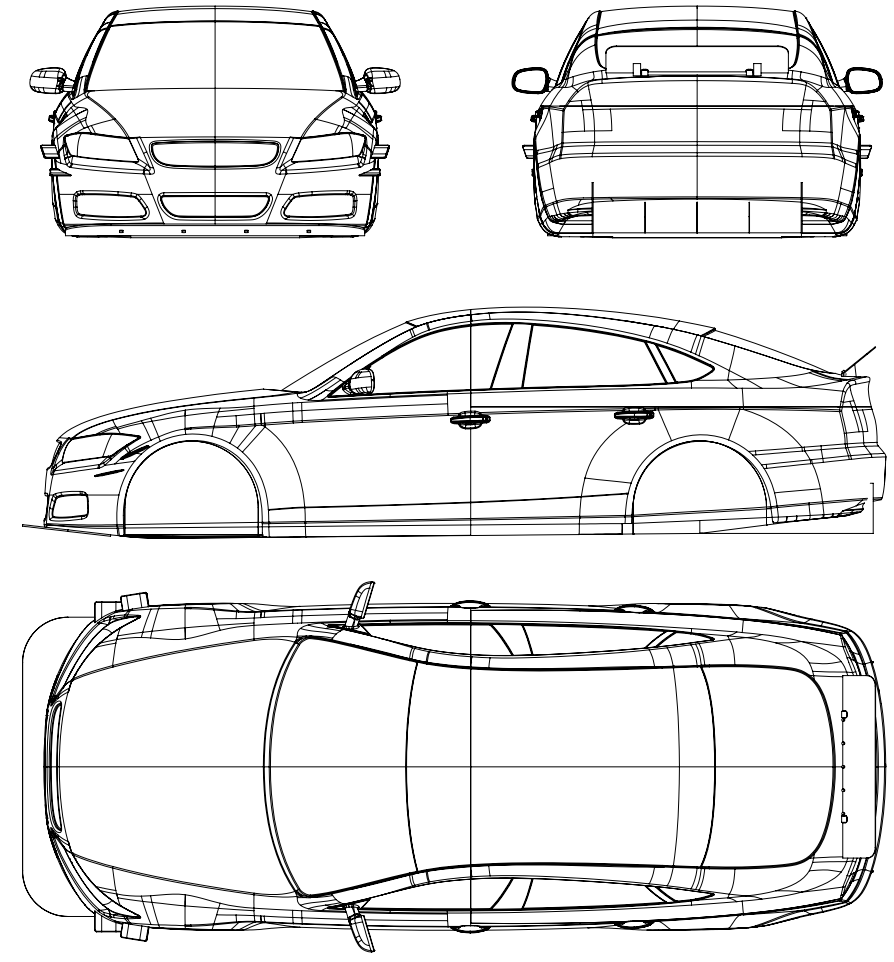

(a)
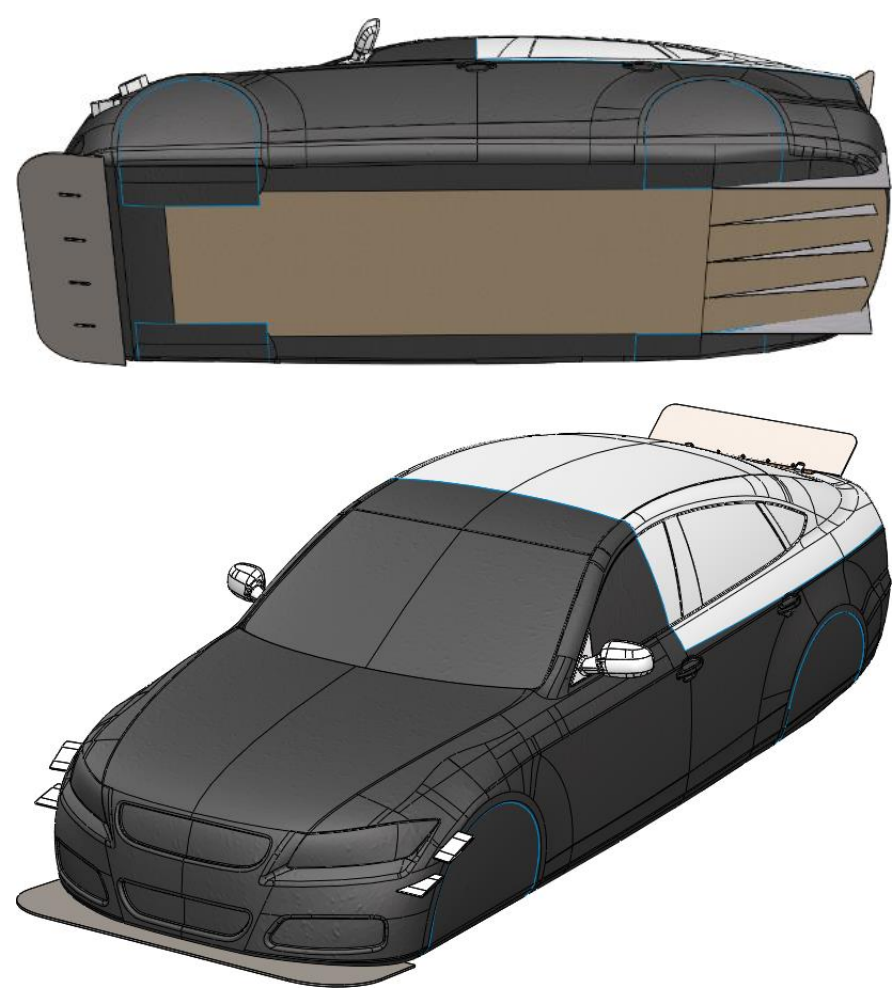

(b)

Figure 9. Illustration of the proposed DrivAer hp-Fastback configuration: (a) projected, standard views; (b) perspective views showing the lower (splitter and diffuser) and upper (strakes and spoiler) vehicle model details. 
downforce gradient as a function of ride height is more significant on the rear part of the body. In comparison to the baseline car and between respective maximum peaks, the DrivAer $h p-F$ configuration improvement was more significant at lower ride heights, in contrast to the front downforce that is more substantial at greater ride heights.

The trade-off between high-downforce and lower-drag, typical in motorsport applications, also seen in this model: the greater downforce generation is associated with a higher drag penalty. The drag data trend is alike to downforce behaviour, and it peaks at $h / h_{0}=0.33\left(C_{D}=\right.$ $0.316)$.

Aerodynamic balance $(A B)$ endorses this configuration as a highperformance automotive case. For the entire range of ride height tested, the aerodynamics balance move only between $A B=38 \%\left(h / h_{0}=\right.$ $0.20)$ to $58 \%\left(h / h_{0}=2.00\right)$. In terms of driving stability, the car would be oversteering at higher ride heights and understeering otherwise by an acceptable margin. However, this range of aerodynamic balance is a significant improvement when compared to the baseline version. Note that the baseline has most of the net downforce applied at the front axle, and its balance is shifted even outside the wheelbase as the ride height increases and the rear axle become under lifting load.

Aerodynamic efficiency $(A E)$ is highly sensitive to ride height and it is mostly driven by the downforce characteristics. At $h / h_{0}=2.00$, the DrivAer $h p-F$ has $A E=2.05$, and it is improved to maximum performance at $h / h_{0}=0.33(A E=3.46)$. The aerodynamic efficiency reduces in lower ride heights as a consequence of the downforce decay mechanism recurrently noted on the baseline and individual component analysis along this paper.

\section{Reynolds number sensitivity of aerodynamic loads}

This section addresses the variation of measured aerodynamics load of this high-performance DrivAer model with Reynolds number $(R e)$. The respective wind tunnel data are displayed in Figure 18.

Measurements were made at five freestream flow velocities $(20,25$, $30,35,40 \mathrm{~m} / \mathrm{s}$, corresponding to Reynolds numbers of 2.07, 2.59, $3.11,3.63,4.15 \times 10^{6}$, respectively. Three model ride heights $\left(h / h_{0}=0.25,1.00\right.$, and 2.00) were tested at each Reynolds number.

The sensitivity of drag coefficient to changes in Reynolds number is low, typically $\Delta C_{D} / C_{D} \leq 1.5 \%$. There is a tendency of drag increment as $R e$ increases. The except is the highest position, which reduces as Re increases, and is the more sensitive ride height to Reynolds number: $\Delta C_{D}=0.005$, for the $R e$ range tested.

Statistical analysis of the baseline configuration had indicated experimental uncertainty of $\Delta C_{D}=0.005$. If considered it as the experimental systematic deviation, the conclusion about different trends in drag is not supported by statistical arguments. Contrariwise, Reynolds number sensibility of the net downforce (and respective components) can be statistically relevant due to the large differences in comparison to the estimated confidence interval.

Net downforce is seen to increase with increasing Reynolds number. Interestingly, if measuring the offset between the ride heights, it can be stated that an increment of $415 \pm 2$ downforce counts is found between the extreme ride height cases $\left(h / h_{0}=2.00 \rightarrow 0.25\right)$, or an intermediate increment of $192 \pm 5$ counts for $h / h_{0}=1.00 \rightarrow 0.25$. It would lead to conclude that $R e$ sensitivity of net downforce coefficient is independent of ride height.

The analysis of downforce components shows that variations due to Reynolds number are balanced differently for each ride height. The total downforce increment can be split as (a) $\Delta C_{L f}=-0.035$ and $\Delta C_{L r}=-0.032$ at $h / h_{0}=0.25$, (b) $\Delta C_{L f}=-0.047$ and $\Delta C_{L r}=$ -0.028 at $h / h_{0}=1.00$; and (c) $\Delta C_{L f}=-0.043$ and $\Delta C_{L r}=-0.021$ at $h / h_{0}=2.00$. It terms of proportional gain, front downforce increase by $9.2 \%, 13.1 \%$, and $13.8 \%$ while rear downforce increase only by $5.7 \%, 7.3 \%$, and $9.7 \%$, both corresponding to $h / h_{0}=0.25,1.00$, and 2.00 .

Therefore, front axle downforce coefficient appears more sensitive to Reynolds number than rear axle downforce coefficient. These Re sensitivity are also dependent of the ride heights: Re-dependency of the front downforce increases as ride height reduces, while the rear downforce is more $R e$-sensitive at higher gap clearance.

In practical terms, the aerodynamic balance has a small sensitivity to Reynolds number $(\triangle A B<1.5 \%)$, particularly when compared to the effect of changes in ride height $(\triangle A B \approx 18 \%$ at any $R e$ number tested).

The results show that aerodynamic efficiency has significant Redependency within the Re number range tested, mostly due to changes in the downforce coefficient. In general terms, aerodynamic efficiency increases as $R e$ number increases: $\triangle A E=8.7 \%, 10.1 \%$, and $11.8 \%$ for $h / h_{0}=0.25,1.00$, and 2.00 , respectively. This data shows that ride height has an impact on the sensitivity of aerodynamic efficiency to changes in Reynolds number.

\section{CONCLUSIONS}

Sub-scale wind tunnel tests have been undertaken to develop a new 4th configuration of the DrivAer reference model to reflect the primary aerodynamic attributes of enclosed-wheel race cars and extend the existing motorsport industry reference database.

A 35\% scale model of an existing DrivAer Fastback configuration was tested over a range of ride heights $\left(0.20 \leq h / h_{0} \leq 2.00\right)$ above a moving ground at zero-yaw. This baseline data was then supplemented by a parametric assessment of typical aerodynamic devices including (i) forebody strakes, (ii) front bumper splitters, (iii) a rear-end spoiler, and (iv) an underbody diffuser. Using this data, a high-performance DrivAer configuration, the DrivAer $h p-F$, was identified and tested over a range of ride heights and Reynolds numbers.

A DrivAer car configuration (FS* ${ }^{*}$ MwoW) was selected as the baseline configuration. Small changes from the original DrivAer geometry relate to the wheel cavities and an extended main underfloor plane. The variation in both the overall and axle load distribution have been measured over a range of ride heights to assess the impact of ride height on aerodynamic balance and efficiency. While drag is less sensitive, with a maximum variation of $3.4 \%$ for the range tested $\left(h / h_{0}=2.00 \rightarrow 0.20\right)$, the net downforce showed a notable increase with only small ride height reductions, with a maximum increase of nearly 2.8 times. The front and rear axle downforce, although different in magnitude, show very similar trends.

Front splitter length made little difference to the downforce compared to the other aerodynamic devices considered. However, the splitters 
tested may not have been at an optimum local angle of incidence, since they were simple flat plates mounted parallel to the underbody surface at the front of the vehicle - this may have reduced potential gains. The splitter configuration did however move the aerodynamic balance forward, as it reduces rear downforce in the same proportion as it increases front axle load, with a minimal impact on drag. Further research is recommended to investigate the effect of the local angle of incidence on the aerodynamic performance of splitters.

The effect of fore body strakes was more significant for motorsport applications. The large, full-set of strakes fitted on the baseline car model improved the maximum aerodynamic efficiency from 2.7 to 3.5 . The assessment of different combinations of strakes indicated that the effects of the lower and upper sets of strakes are not additive when in used in close proximity to each other; the interference effects are similar to those experienced by double-element wings. It also highlighted the significance of the strake mounting location and angle of incidence, especially when multi-element strakes are used.

The impact of rear-end spoilers on aerodynamic performance was very marked, particularly in relation to rear axle loading. There is a clear trend in downforce variation with spoiler size. An assessment of the influence of spoiler angle indicated a possible optimum value for maximum downforce of between $40 \mathrm{deg}$ and $60 \mathrm{deg}$. Further studies with smaller increments in spoiler angle are recommended.

The aerodynamic characteristics of diffusers are seen to be relatively complex but also demonstrate the potential for significant aerodynamic gains. Farthest from the ground, the downforce magnitude is proportional to spoiler angle (0 deg, $5 \mathrm{deg}$, baseline case, $10 \mathrm{deg}$, and $16 \mathrm{deg}$, in ascending order of downforce magnitude). When the vehicle is closer to the ground plane, the trends in drag and rear downforce with changing diffuser angle become more complex. The range of maximum net downforce is found between $0.25<h / h_{0}<$ 0.33 for all cases, and in the following ascending ranking: $0 \mathrm{deg}$, $16 \mathrm{deg}$, baseline case, $5 \mathrm{deg}, 10 \mathrm{deg}$. Note that the baseline model has an underfloor slant angle of $7.1 \mathrm{deg}$, and its loading characteristics resemble what would be expected from a testing case of $\operatorname{diff} A=$ $7 \mathrm{deg}$. The assessment of diffusers included the effect of adding longitudinal separators on the diffuser surface and the results show an added degree of complexity in the variation of aerodynamic load. The reason for the loss in front downforce is unclear, but the behaviour of the rear downforce peaks support the theory that diffuser vortex breakdown might be delayed as the body approaches the ground plane.

The proposed DrivAer $h p-F$ configuration, utilising the optimised aerodynamic configuration based on the earlier tests, showed an increment in downforce coefficient of $\left|\Delta C_{L}\right|=0.495$ over the ride height range of $h / h_{0}=2.00 \rightarrow 0.20$. The corresponding increase in drag coefficient is $\left|\Delta C_{D}\right|=0.022$ over the same ride height range. In terms of downforce distribution, the rear axle downforce is more sensitive to ride height changes than the front axle.

The optimum ride height of this model is seen to be $h / h_{0}=0.33$, where the maximum drag increment is almost $10 \%$ and net downforce is nominally twice the magnitude measured at $h / h_{0}=2.00$. The downforce distribution shows similar trends and peak position, however proportional and absolute gains at the rear axle are more significant than the front downforce. Aerodynamic efficiency $(A E)$ has similar characteristics to the net downforce behaviour, and varies in the range of $2.06<A E<3.46$, while aerodynamic balance (AB) changes more linearly from $A B=61 \%$ to $42 \%$ when readjusting ride height from $h / h_{0}=2.00$ to 0.33 .
The DrivAer $h p-F$ configuration has been tested over a range of Reynolds numbers (between 2.07 to $4.15 \times 10^{6}$, based on model length), in order to support correlation between wind tunnel data and full scale on-road vehicle aerodynamic performance. The data suggests that changes in Reynolds number have: (i) a different impact on the different aerodynamic coefficients, and (ii) that $R e$ sensitivity can be also a function of ride height for specific properties. The trends in the variation of aerodynamic coefficients with $R e$ number support the requirement for measurements on the DrivAer configuration over an extended range.

Reynolds number sensitivity of the DrivAer $h p-F$ aerodynamic loads was assessed at five freestream speeds and at three ride heights. The variation in the drag coefficient data at each ride height is within the measurement repeatability. For downforce-related characteristics, the three ride heights presented similar $R e$ influence. Downforce (net and components) increases as Re increases, and so does the aerodynamic efficiency. However, front downforce is more sensitive than the rear component. This explains why the aerodynamic balance moves rearwards as Re increases.

Based on the experimental dataset, there would appear to be negligible dependence between $R e$ number and ride height for this configuration, if considered in terms of incremental changes rather than proportional. Potentially significant is the magnitude of the transcritical Reynolds number $\left(R e_{t c}\right)$. The downforce data (net, front and rear axle components) appear to have different $R e_{t c}$ magnitudes, as rear downforce reaches $R e$ independence while front downforce shows that $R e_{t c}$ would appear to be greater than $4.15 \times 10^{6}$.

The aerodynamic characteristics of motorsport configurations routinely demonstrate that there is a trade-off between high-downforce and low-drag configuration (e.g. increasing downforce is usually associated with a drag penalty). The data presented here for this configuration is consistent with the general trend, however the initial objective of developing a high-performance fastback version of the DrivAer configuration was achieved. In comparison to the baseline model at optimum ride height, the proposed high-performance configuration more than doubled the net downforce, while aerodynamic efficiency is improved by $\triangle A E=0.8$ (from 2.7 to 3.5) while generating $C_{L}>1.00$. The generation of downforce was proportionally more significant at the rear axle, which improved the aerodynamic balance of the baseline $(A B>80 \%)$ to a more practical value $(A B \approx 41 \%)$ on the DrivAer $h p-F$.

In line with the open-access concept of the DrivAer model, the geometry CAD files related to this paper will be made available online at Cranfield Online Research Data (CORD, [27]). This initiative aims to support experimental and computational studies in automotive aerodynamics.

\section{REFERENCES}

[1] DTM website. Available at https://www.dtm.com/sites/default/ files/pflicht teaser2.jpg, Oct 2017.

[2] AutoGuide website. "NASCAR Drivers Transform the Toyota Camry". Available at http://www.autoguide.com/blog/wpcontent/gallery/toyota-camry-2017-sema-show-officialgallery/toyota-camry-2017-sema-show-rutledge-11.jpg, Nov 2017.

[3] Katz, J. "Race Car Aerodynamics: Designing for Speed". $2^{\text {nd }}$ edition. Cambridge: Bentley Publishers, 2006. ISBN 9780837601427. 
[4] Singh, R. "CFD Simulation of NASCAR Racing Car Aerodynamics". SAE Technical Paper 2008-01-0659, 2008, doi:10.4271/2008-01-0659.

[5] Katz, J. and Cain, K.P. "Rapid, Low-Cost, Aerodynamic Development of a High-Performance Sports Car". SAE Technical Papers 2011-01-2821, 2011, doi:10.4271/2011-01$\underline{2821}$.

[6] Garry, K. and Le Good, G. "An Investigation of the Sensitivity of Rear Wing Orientation for Saloon Race Cars". SAE Technical Paper 2005-01-1018, 2005, doi:10.4271/2005-01$\underline{1018 .}$

[7] Hellman, S., et al. "PIV Analysis Comparing Flow Past NASCAR COT Rear Wing and Spoiler Traveling Forward and Backwards". SAE Technical Papers 2011-01-1432, 2011, doi:10.4271/2011-01-1432.

[8] Le Good, G. et al. "The Design of Systematic Add-on Configuration Changes for the DrivAer Body and their Aerodynamic Characteristics". In: IMechE International Conference on Vehicle Aerodynamics, Coventry, Sep 2016.

[9] Cheng, S. and Mansor, S. "Influence of Rear-roof Spoiler on the Aerodynamic Performance of Hatchback Vehicle". MATEC Web of Conferences 90, 01027, 2017, doi:10.1051/matecconf/20179001027.

[10] Ahmed, S.R. "Influence of Base Slant on the Wake Structure and Drag of Road Vehicles". Trans. ASME. Journal of Fluids Engineering, 105, p.429-434, 1983, doi:10.1115/1.3241024.

[11] Fukuda, H., et al. "Improvement of Vehicle Aerodynamics by Wake Control”. JSAE Review, v16 (2), 1995: p. 151-155. doi: 10.1016/0389-4304(95)00007-T.

[12] Singh, R. and Golsch, K. "A Downforce Optimization Study for a Racing Car Shape". SAE Technical Papers, 2005-01-0545, 2005, doi: 10.4271/2005-01-0545.

[13] Cooper, K. R., et al. "The Aerodynamic Performance of Automotive Underbody Diffusers". SAE Technical Papers, 980030, 1998, doi:10.4271/980030.

[14] Cooper, K. R. and Syms, J. "Selecting Automotive Diffusers to Maximise Underbody Downforce". SAE Technical Papers, 2000-01-0354, 2000, doi:10.4271/2000-01-0354.

[15] Zhang, X., Toet W. and Zerihan J. "Ground Effect Aerodynamics of Race Cars". Applied Mechanics Reviews, v59 (1-6), 2110263, 2006, p. 33-48, doi:10.1115/1.2110263.

[16] Hu, X., et al. "Influence of Different Diffuser Angle on Sedan's Aerodynamic Characteristics". Physics Procedia, v22, 2011, p. 239-245. doi:10.1016/j.phpro.2011.11.038.

[17] Jowsey, L. and Passmore, M. "Experimental Study of MultipleChannel Automotive Underbody Diffusers". Proceedings of the Institution of Mechanical Engineers, Part D: Journal of Automobile Engineering. 2010; 224 (7): pp.865-879, doi:10.1243/09544070JAUTO1339.

[18] Xingjun, H., et al. "Design and Aerodynamic Assessment of Diffuser with Longitudinal Separators for Underbody of Sedan". Applied Mechanics and Materials. 2012; 215-216: pp. 10331037, doi:10.4028/www.scientific.net/AMM.215-216.1033.

[19] Heft, A., Indinger, T., Adams, N. "Introduction of a new realistic generic car model for aerodynamic investigations". SAE Technical Paper 2012-01-0168, 2012, doi:10.4271/201201-0168

[20] Mack, S., Indinger, T., Adams, N., Blume, S., Unterlechner, P. "The Interior Design of a 40\% Scaled DrivAer Body and First Experimental Results". ASME 2012, July 8-12, 2012, Puerto Rico, USA, FEDSM2012-72371. doi:10.1115/fedsm2012$\underline{72371}$.

[21] Collin, C., Mack, S., Indinger, T., Mueller, J. “A Numerical and Experimental Evaluation of Open Jet Wind Tunnel Interferences using the DrivAer Reference Model". SAE Int. J. Passeng. Cars - Mech. Syst. 9(2):657-679, 2016, doi:10.4271/2016-01-1597.

[22] DrivAer Model: “Geometry". Institute of Aerodynamics and Fluid Mechanics. Technical University of Munich. Available at: http://www.aer.mw.tum.de/en/research-groups/automotive/ drivaer/geometry/.

[23] Soares, R. F. "Drag of road cars: cost-effective CFD setup, proposal of an aerodynamic concept and case studies". 2015. 197p. Master Thesis, Universidade Federal de Uberlândia, Uberlândia, 2015, doi:10.13140/RG.2.1.3591.1765, UFU.

[24] Soares, R., Garry, K., and Holt, J., "Comparison of the Far-Field Aerodynamic Wake Development for Three DrivAer Model Configurations using a Cost-Effective RANS Simulation”, SAE Technical Paper 2017-01-1514, 2017, doi:10.4271/2017-011514.

[25] Aerotech A.T.E. Ltd. "Specification 9304-1. General Specification of 3 or 6 Component Internal Strain Gauged Balances for Race Car Models". Heathfield (E.Sussex).

[26] Howell, J. and Le Good, G. "The Influence of Aerodynamic Lift on High Speed Stability" SAE Technical Paper 1999-01-0651, 1999, doi:10.4271/1999-01-0651.

[27] Soares, R.F. et al. "DrivAer hp-F: the CAD geometry pack". Cranfield Online Research Data (CORD), 2018, doi:10.17862/cranfield.rd.c.3969120.

[28] Soares, R.F. et al. Dataset for SAE 2018-01-0725 "On the Aerodynamics of an Enclosed-Wheel Racing Car: an assessment and proposal of add-on devices for a fourth, high-performance configuration of the DrivAer model". Cranfield Online Research Data (CORD), 2018, doi:10.17862/cranfield.rd.c.3969120.

\section{CONTACT INFORMATION}

Renan F. Soares

Researcher, $\mathrm{PhD}$ student in Aerospace

Email: r.soares@cranfield.ac.uk

LinkedIn: www.linkedin.com/in/renanfranciscosoares

School of Aerospace, Transport and Manufacturing (SATM)

Building 83, Cranfield University

Cranfield, Bedfordshire, MK43 0AL, United Kingdom.

\section{ACKNOWLEDGEMENTS}

The authors are thankful to the Brazilian National Council for Scientific and Technological Development $(\mathrm{CNPq})$ for the research scholarship.

Special thanks are given to Paul Dancer, Karl Gerhard, and Lynton Banks-Davies, for contributions to model adaptations, manufacturing, and experimental testing.

\section{DEFINITIONS/ABBREVIATIONS}

$\begin{array}{ll}\boldsymbol{A}_{\text {ref }} & \text { Reference Frontal Area } \\ \boldsymbol{A B} & \text { Aerodynamic Balance }\end{array}$


$C_{D} \quad$ Drag coefficient

woW with no wheels; with wheel cavity lids.

$C_{L}$

Lift coefficient

woWS

with no wheel struts

$C_{L f} \quad$ Lift coefficient, front (axle)

$C_{L r} \quad$ Lift coefficient, rear (axle)

$\delta t$

Tyre deformation (virtually used for ground plane definition)

CAD Computer-aided design

CFD Computational Fluid Dynamics

$\boldsymbol{\rho}_{\text {ref }} \quad$ Reference density

\section{CORD Cranfield Online Research Data}

CS Car scale

$\operatorname{diff} \boldsymbol{A} \quad$ Nominal diffuser angle

$\boldsymbol{F}_{\boldsymbol{D}}, \boldsymbol{D} \quad$ Drag force

$\boldsymbol{F}_{\boldsymbol{L}}, \boldsymbol{L} \quad$ Lift force

GS on Ground simulation (relative ground movement and wheels rotation, when included)

$\boldsymbol{h} \quad$ Ride height

$\boldsymbol{h} / \boldsymbol{h}_{\boldsymbol{o}} \quad$ Normalised ride height

$\boldsymbol{L} \quad$ Reference car length

Ma Mach number

$\boldsymbol{P}_{\text {ref }} \quad$ Reference pressure

Re Reynolds number

$\boldsymbol{R}_{\boldsymbol{t c}} \quad$ Reynolds number, transcritical

$S$

$S^{*} \quad$ Smooth underbody (modified, Cranfield version)

SEP off with no longitudinal separators (flat diffuser)

SEP on with longitudinal separators

$\boldsymbol{s p} \boldsymbol{A} \quad$ Nominal angle of incidence for the spoiler plate

$\boldsymbol{s p L} \quad$ Nominal size (length) for the spoiler plate

$\boldsymbol{U}_{\text {ref }} \quad$ Reference velocity

$\boldsymbol{w} \boldsymbol{M} \quad$ with mirrors

wTS with top strut 


\begin{abstract}
APPENDIX
The experimental results described in this paper are presented in graph format in this appendix section.

A unique reference area $\left(A_{\text {ref }}\right)$ is used to normalise all aerodynamic forces for two reasons: (i) except for the forebody strakes, all add-ons cases implicates an identical projected frontal area, and (ii) the use of a same reference area allows for a better evaluation of aerodynamic performance.

All experimental data are under intrinsic influences from the experimental testing facility, such as (a) the top strut support (wTS) and (b) closedtesting section blockage ratio of nearly $10.2 \%$ (minor variation due to top strut displacement). The latter was not corrected in order to offer flexibility to research colleagues to adopt the blockage corrector that they might find more appropriate. Additionally, this uncorrected experimental data can be used for CFD validation purposes, as the same nominal freestream and air properties can directly be applied in cases where the experimental domain is replicated (i.e. fundamental principle in CFD validation procedure: computational replication of experimental conditions and constraints).
\end{abstract}

Legend notation of "Baseline" refers to the baseline case (FS"wWwoW, GSon), while "HPBaseline" refers to the high-performance configuration (DrivAer $h p$-Fastback).

\title{
I - EXPERIMENTAL RESULTS
}

\section{Front bumper splitter}

Figure 10. Front bumper splitter: influence of splitter size on aerodynamic loads.

\section{Forebody lateral strakes}

Figure 11. Forebody lateral strakes: influence of strake size on aerodynamic loads.

Figure 12. Forebody lateral strakes: influence of assembly set on aerodynamic loads.

\section{Rear-end spoiler}

Figure 13. Rear-end spoiler: influence of spoiler angle on aerodynamic loads.

Figure 14. Rear-end spoiler: influence of spoiler size on aerodynamic loads.

\section{Underfloor diffuser}

Figure 15. Underbody diffuser: influence of the diffuser angle on aerodynamic loads.

Figure 16. Underbody diffuser: influence of longitudinal separators on aerodynamic loads.

\section{DrivAer high-performance Fastback configuration}

Figure 17. High-performance Fastback DrivAer configuration: comparison of aerodynamic loads against the standard version. Figure 18. High-performance Fastback DrivAer configuration: Reynolds number sensitivity of aerodynamic loads.

\section{III - DIGITAL DATASET}

Soares, R. et al. Dataset for SAE 2018-01-0725 "On the Aerodynamics of an Enclosed-Wheel Racing Car: an assessment and proposal of addon devices for a fourth, high-performance configuration of the DrivAer model”. Cranfield Online Research Data (CORD), 2018, doi: $10.17862 /$ cranfield.rd.c. 3969120.

Dataset for this SAE Technical Paper 2018-01-0725, which will include:

- Experimental results (Figures 10 to 18 ) in spreadsheet format.

- Summary of experimental testing conditions per run.

- Details of statistical analysis per blocking factor (i.e. group of testing cases).

- Suggestion of corrected force coefficients due to wall interference (wind tunnel area blockage of $\sim 10.2 \%$ ). 

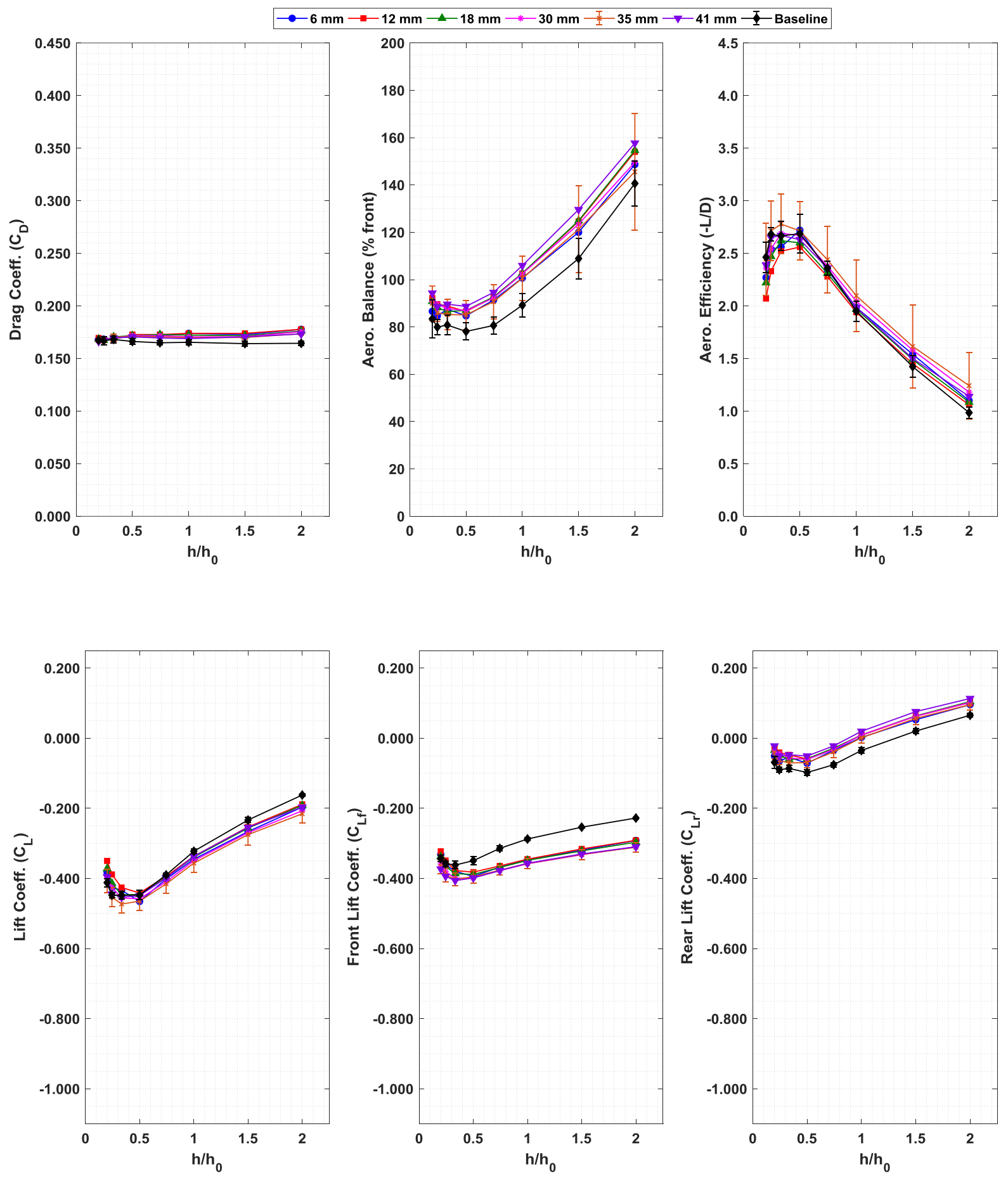

Figure 10. Front bumper splitter: influence of splitter size on aerodynamic loads. 

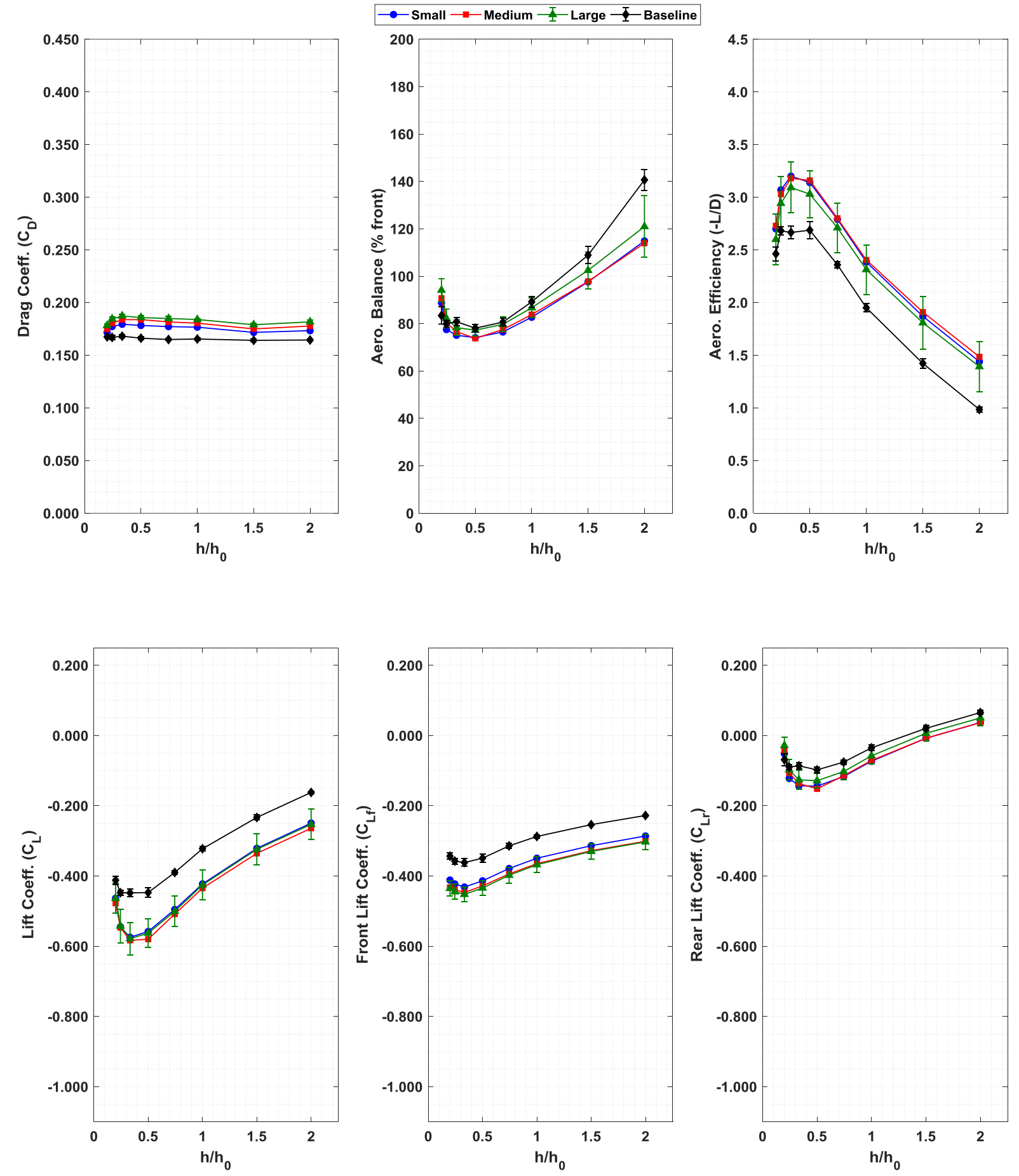

Figure 11. Forebody lateral strakes: influence of strake size on aerodynamic loads. 

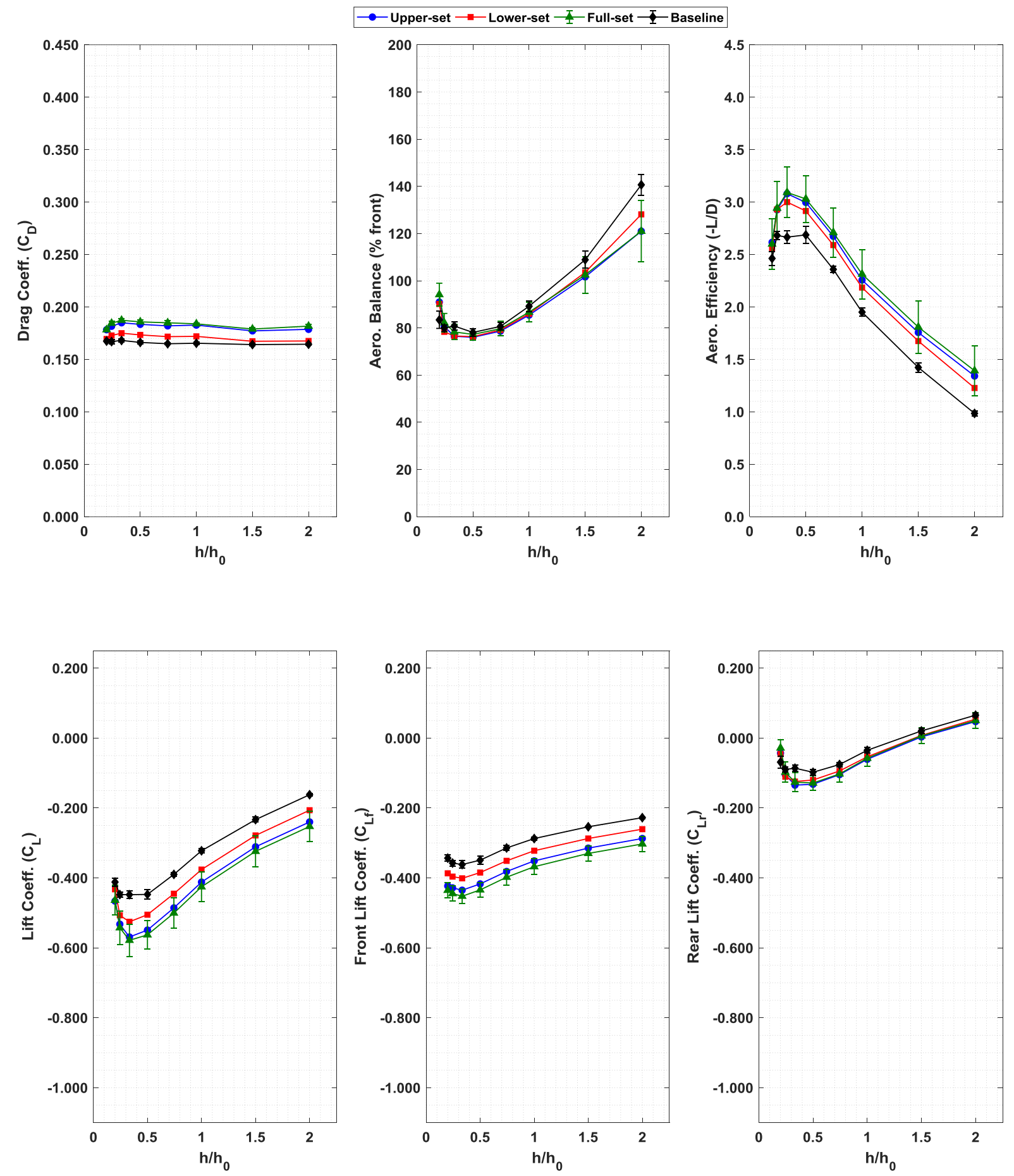

Figure 12. Forebody lateral strakes: influence of assembly set on aerodynamic loads. 

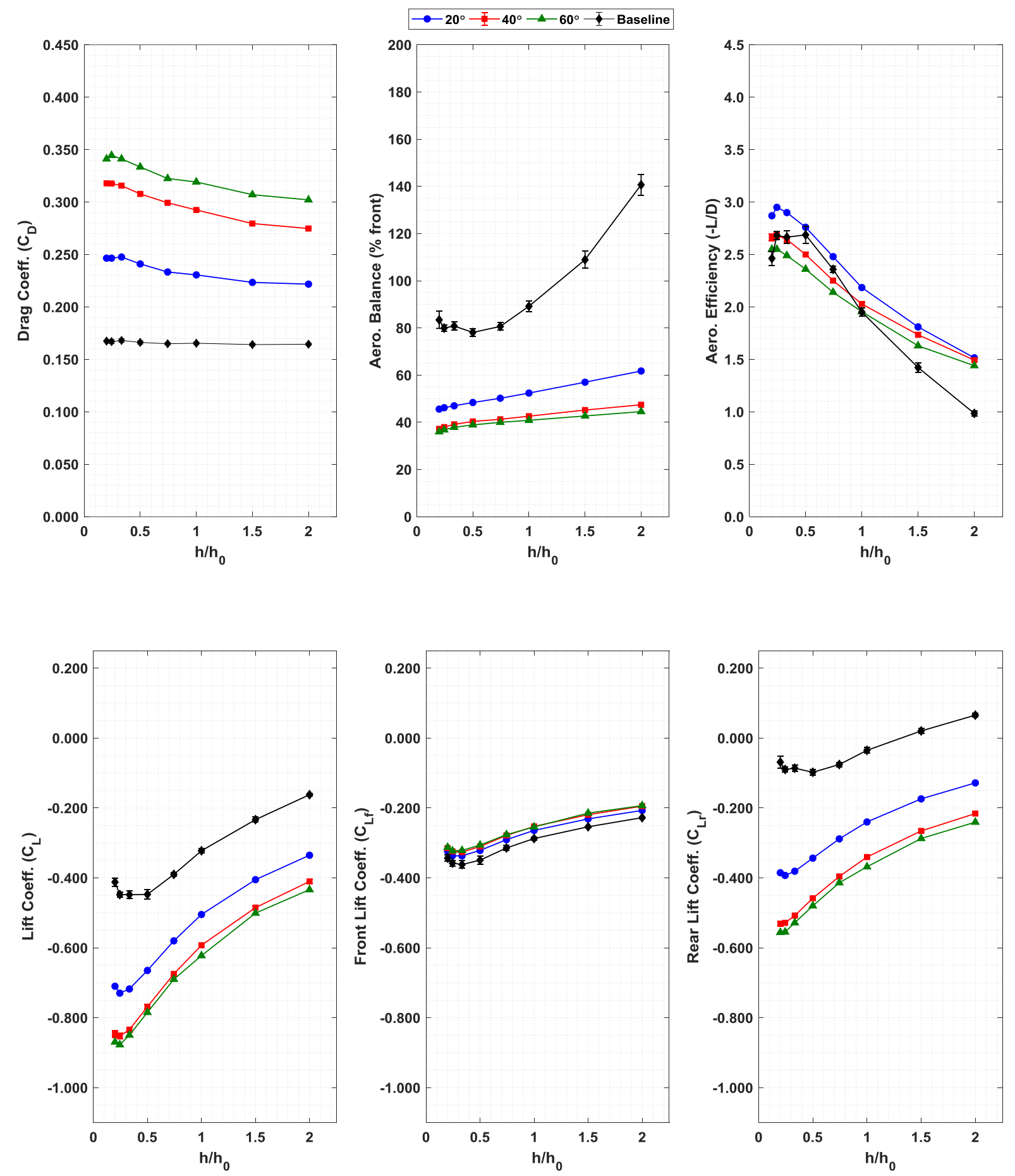

Figure 13. Rear-end spoiler: influence of spoiler angle on aerodynamic loads. 

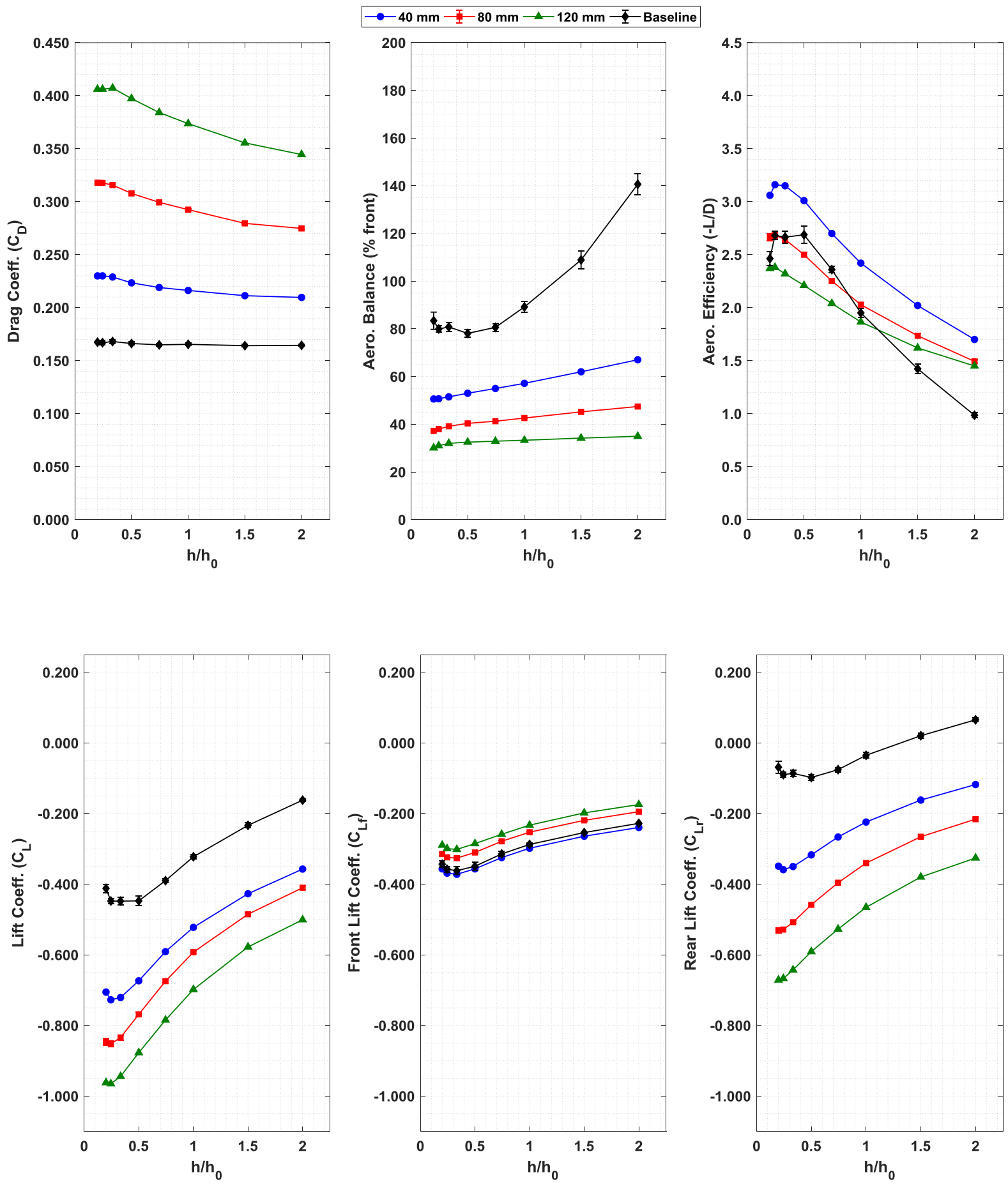

Figure 14. Rear-end spoiler: influence of spoiler size on aerodynamic loads. 

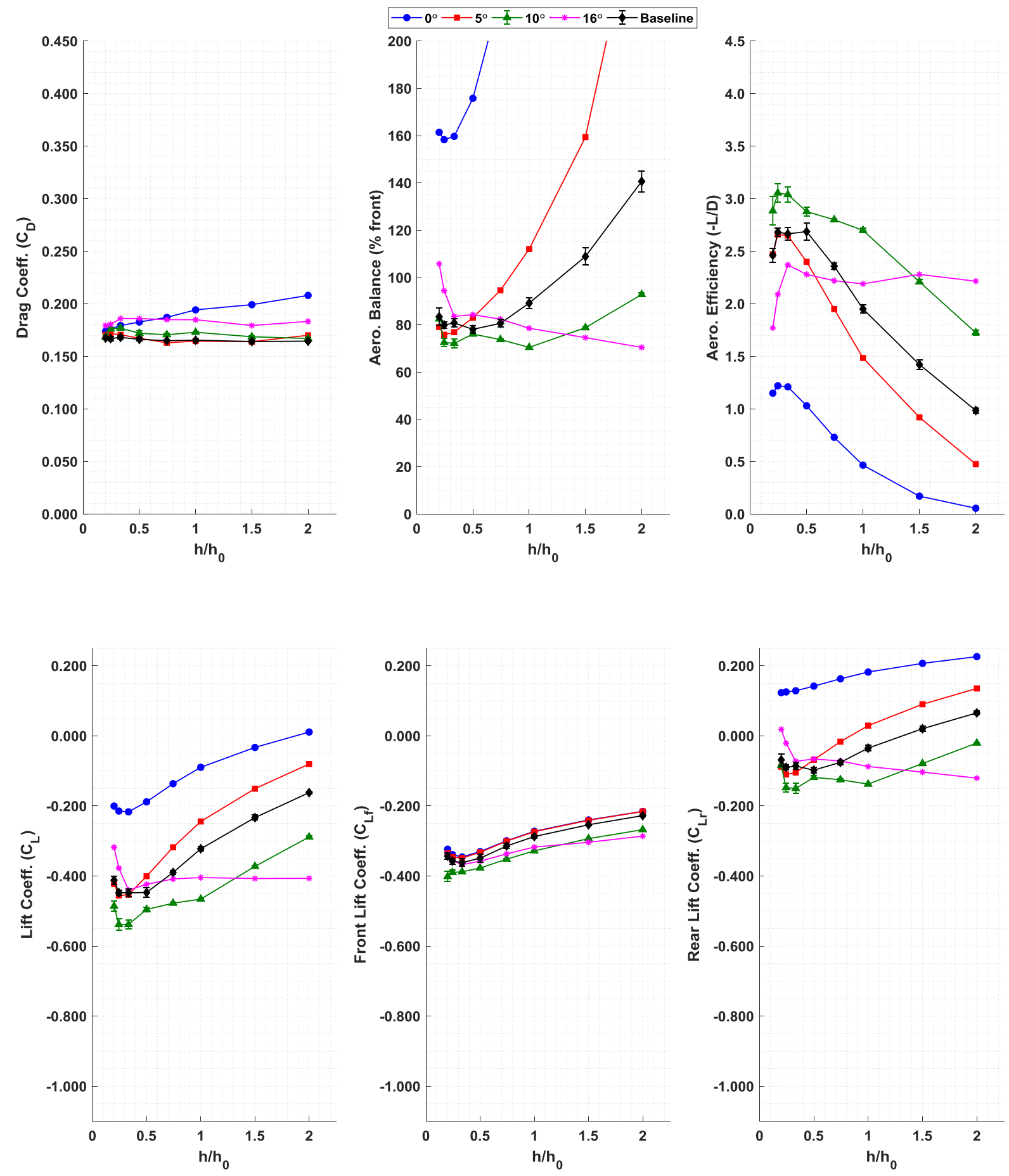

Figure 15. Underbody diffuser: influence of the diffuser angle on aerodynamic loads. 

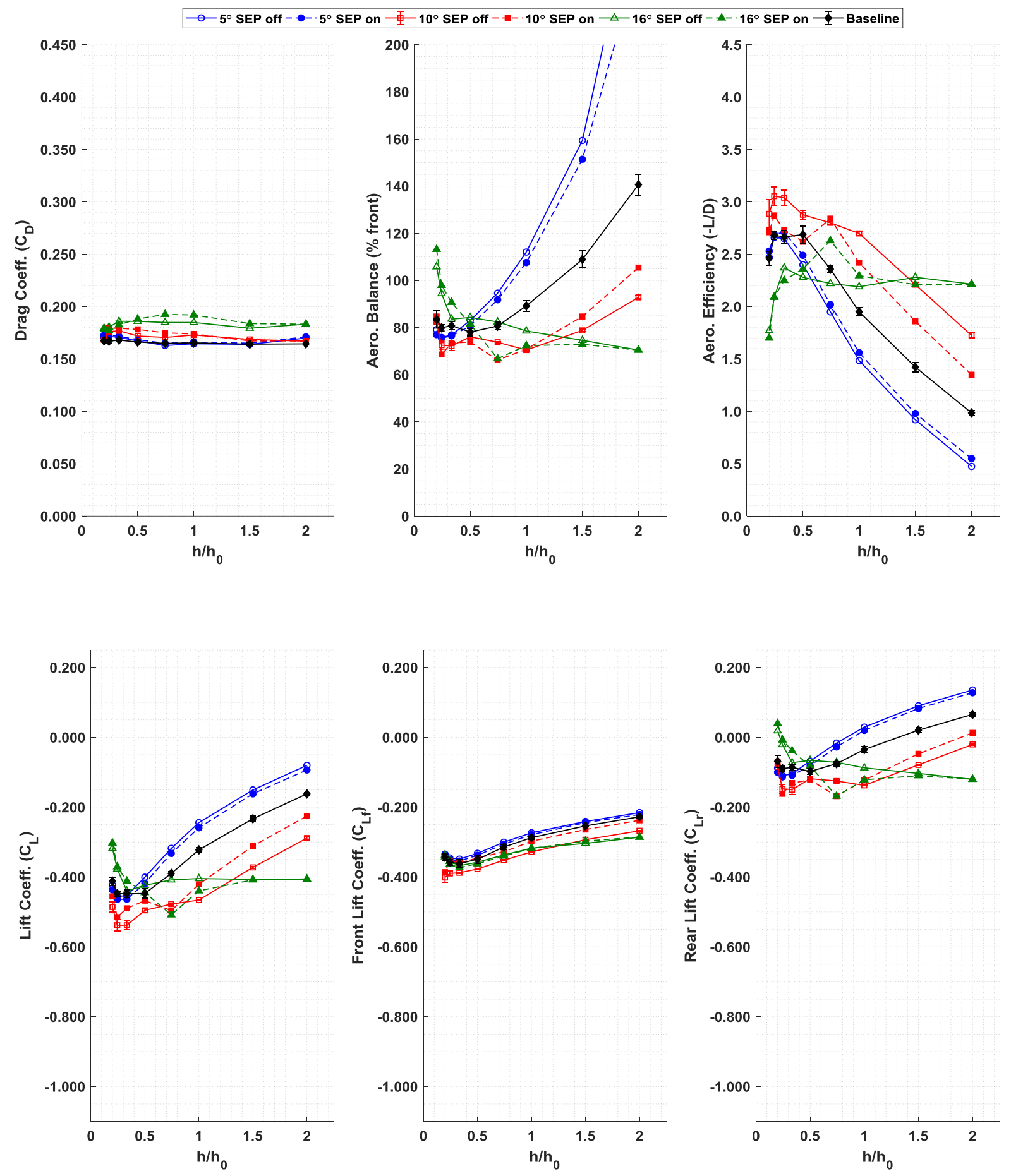

Figure 16. Underbody diffuser: influence of longitudinal separators on aerodynamic loads. 

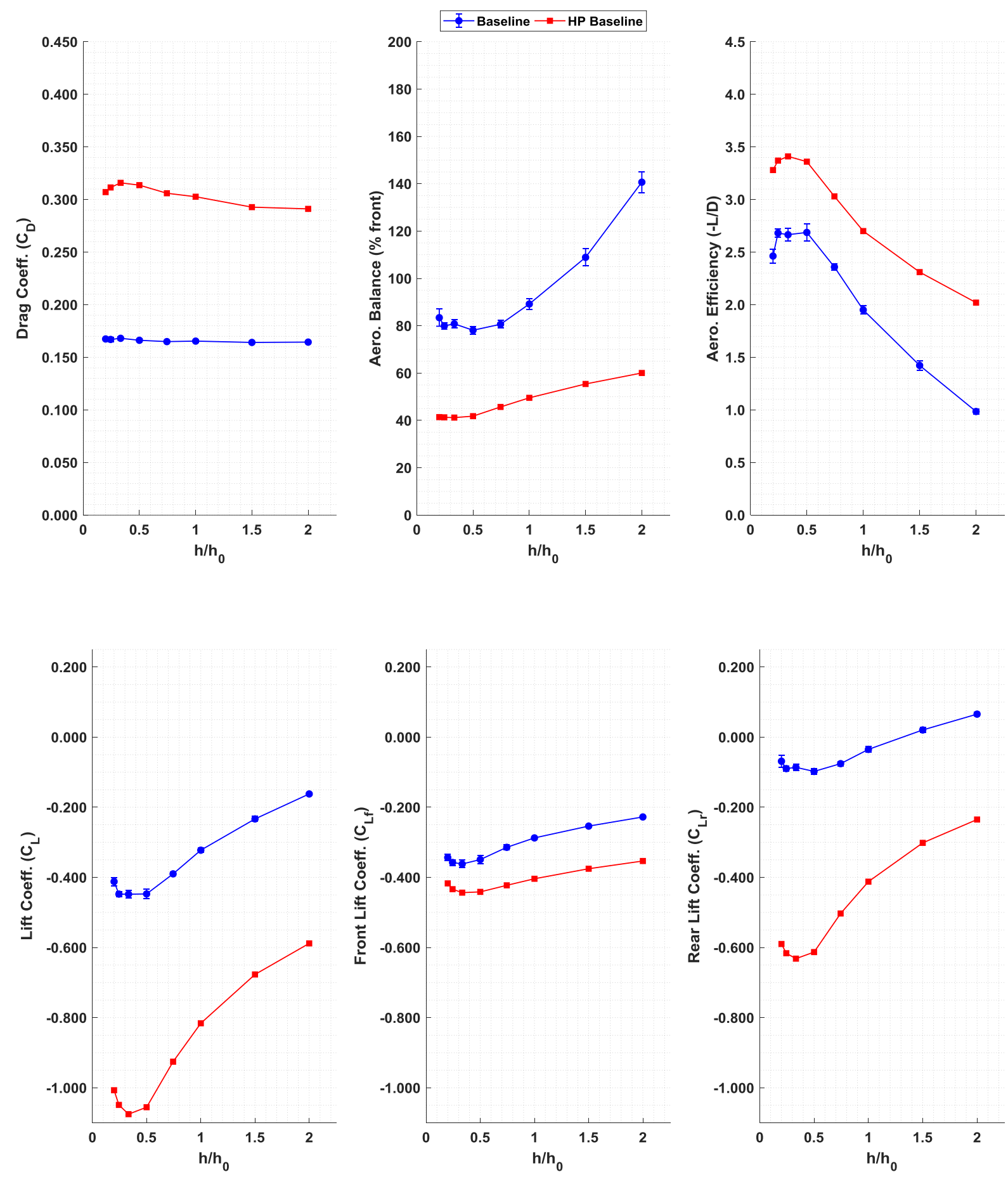

Figure 17. High-performance Fastback DrivAer configuration: comparison of aerodynamic loads against the standard version. 

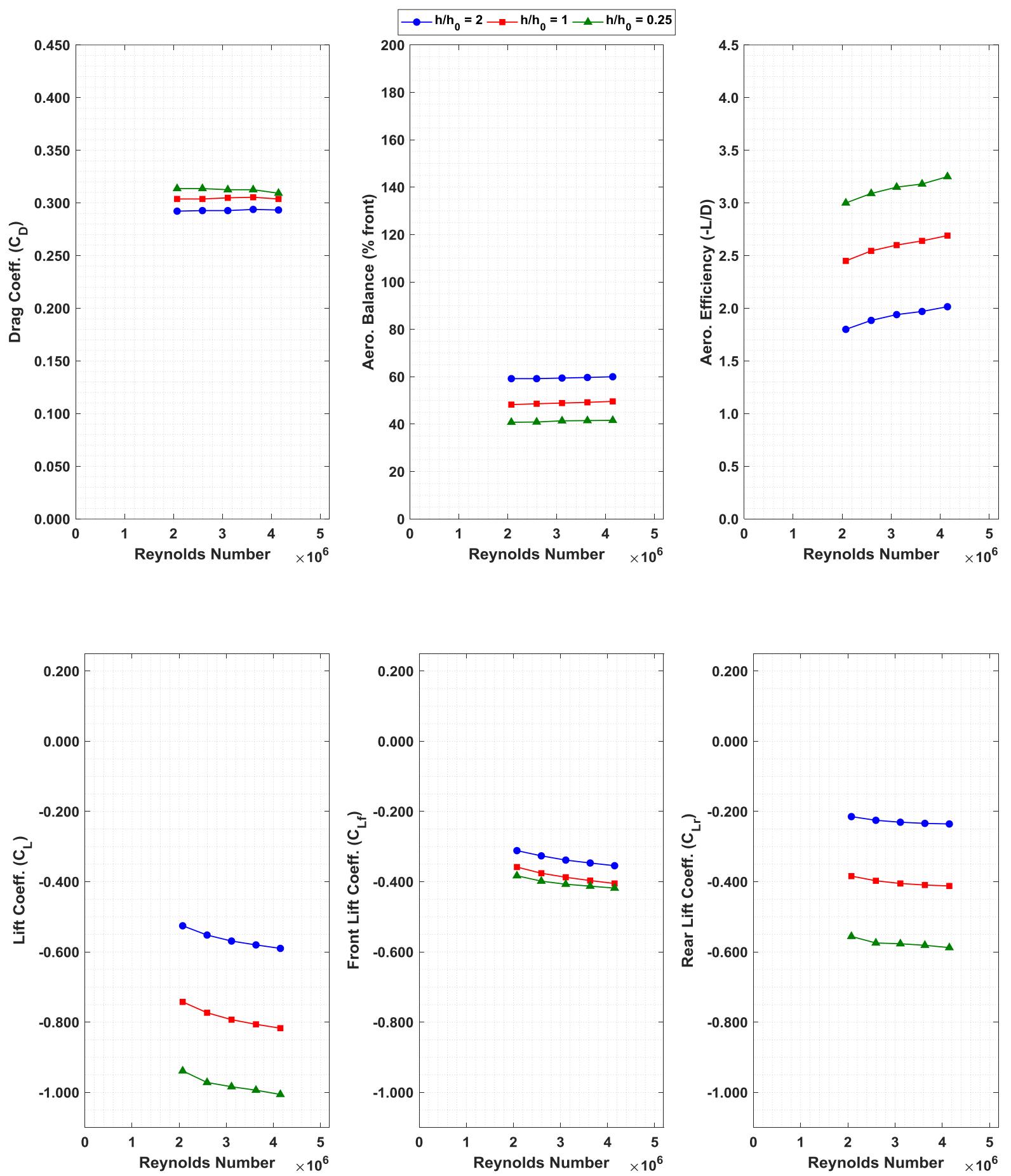

Figure 18. High-performance Fastback DrivAer configuration: Reynolds number sensitivity of aerodynamic loads. 


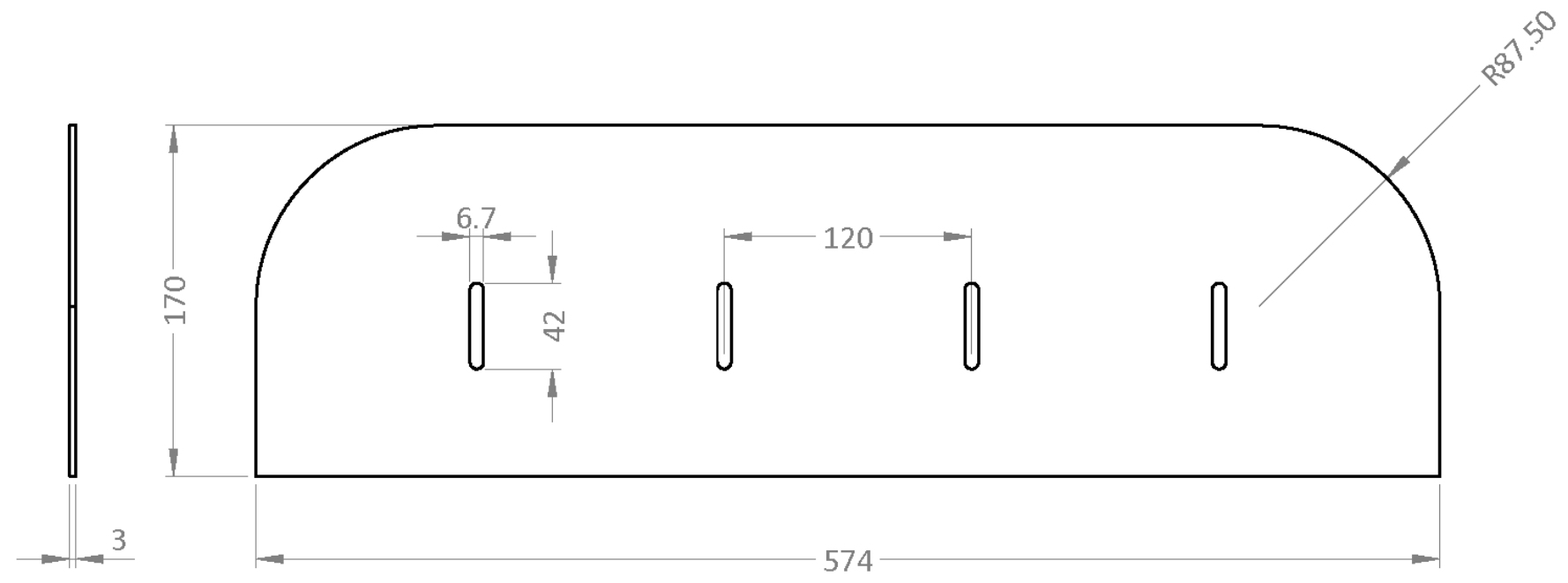

Figure 19. Front bumper splitter plate. Dimensions in $m m$, for a 35\%-scaled DrivAer model.
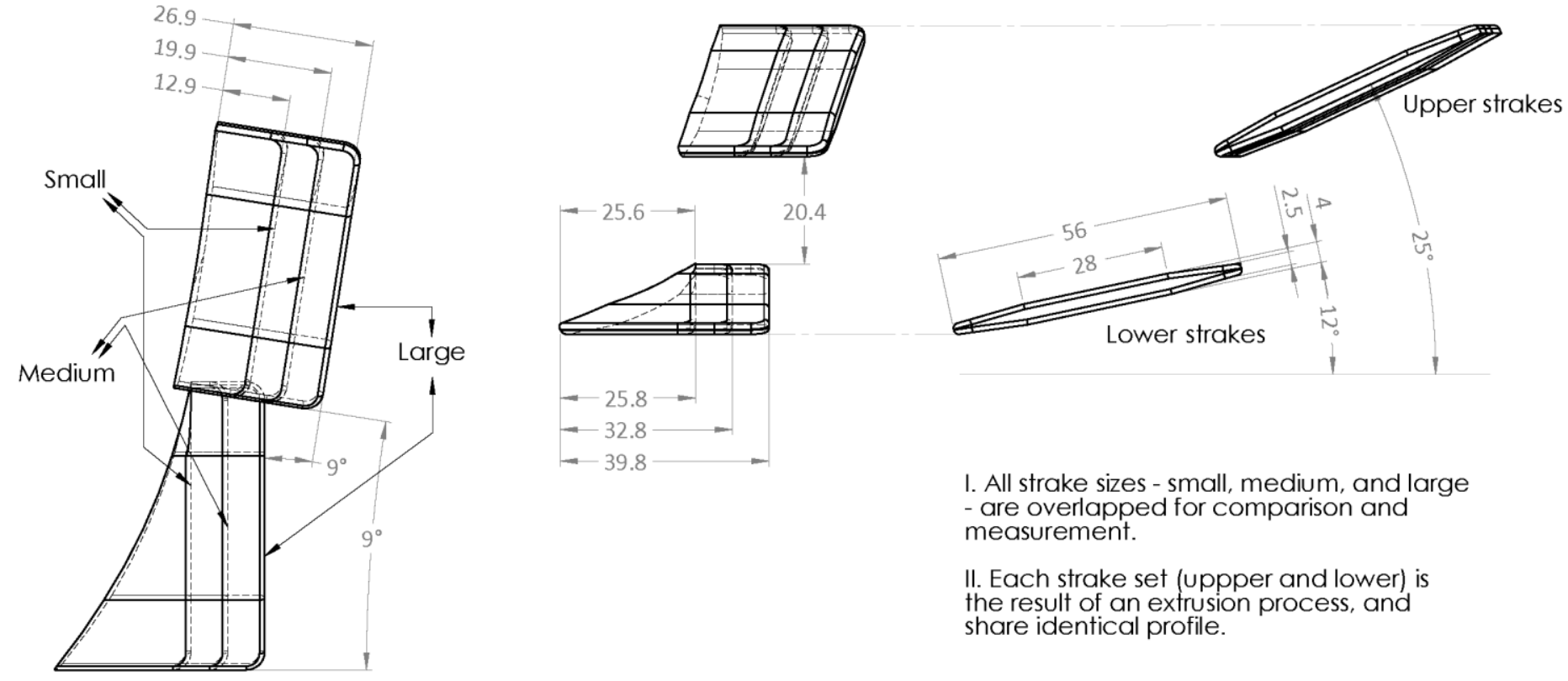

I. All strake sizes - small, medium, and large
- are overlapped for comparison and measurement.

II. Each strake set (uppper and lower) is the result of an extrusion process, and share identical profile.

Figure 20. Forebody lateral strakes. Top, front, and side views (from left- to right-hand side). Dimensions in $m m$, for a 35\%-scaled DrivAer model. 

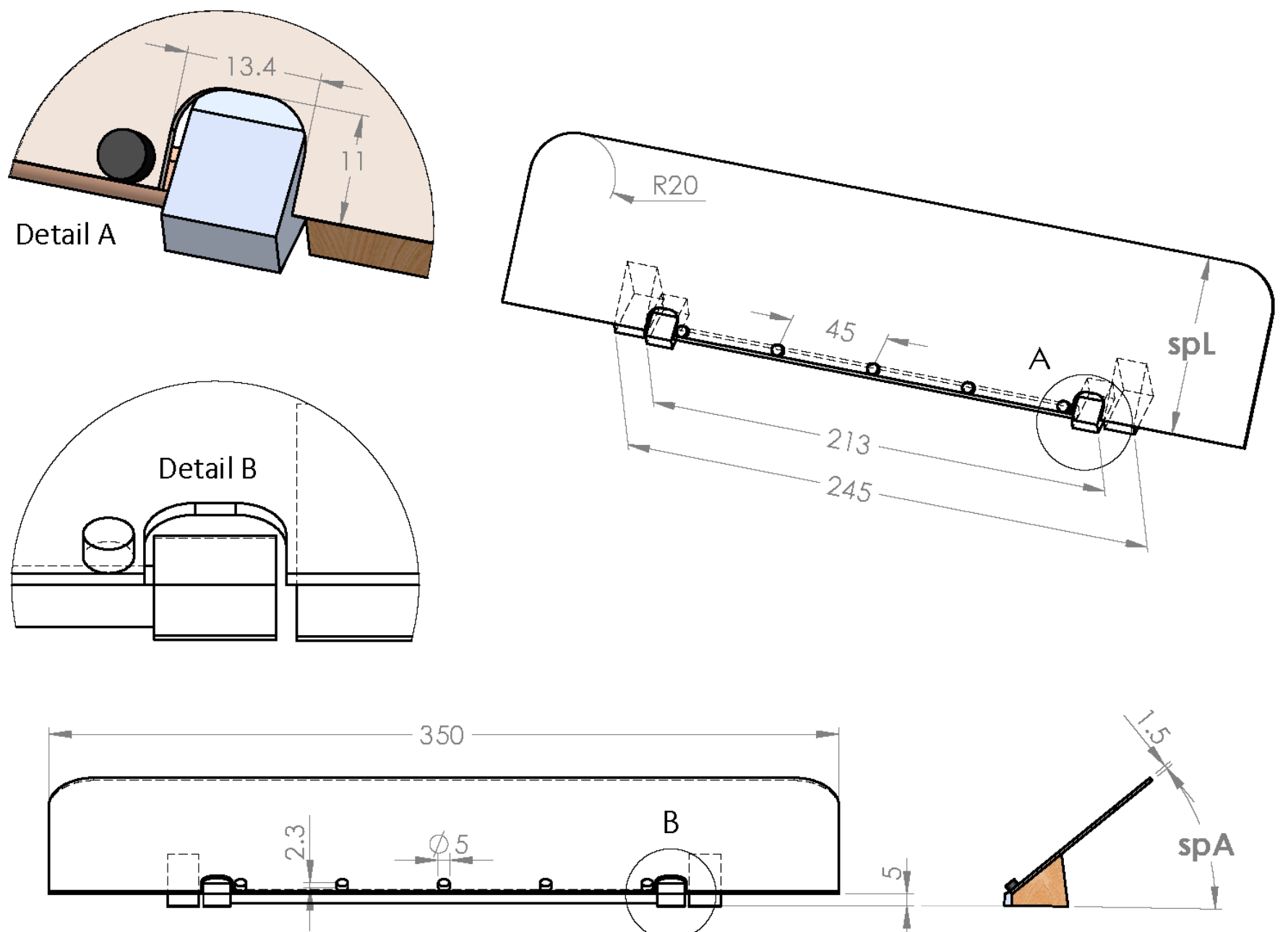

Figure 21. Rear spoiler set. $s p L$ and $s p A$ are the parameters tested. Dimensions in $m m$, for a 35\%-scaled DrivAer model. 

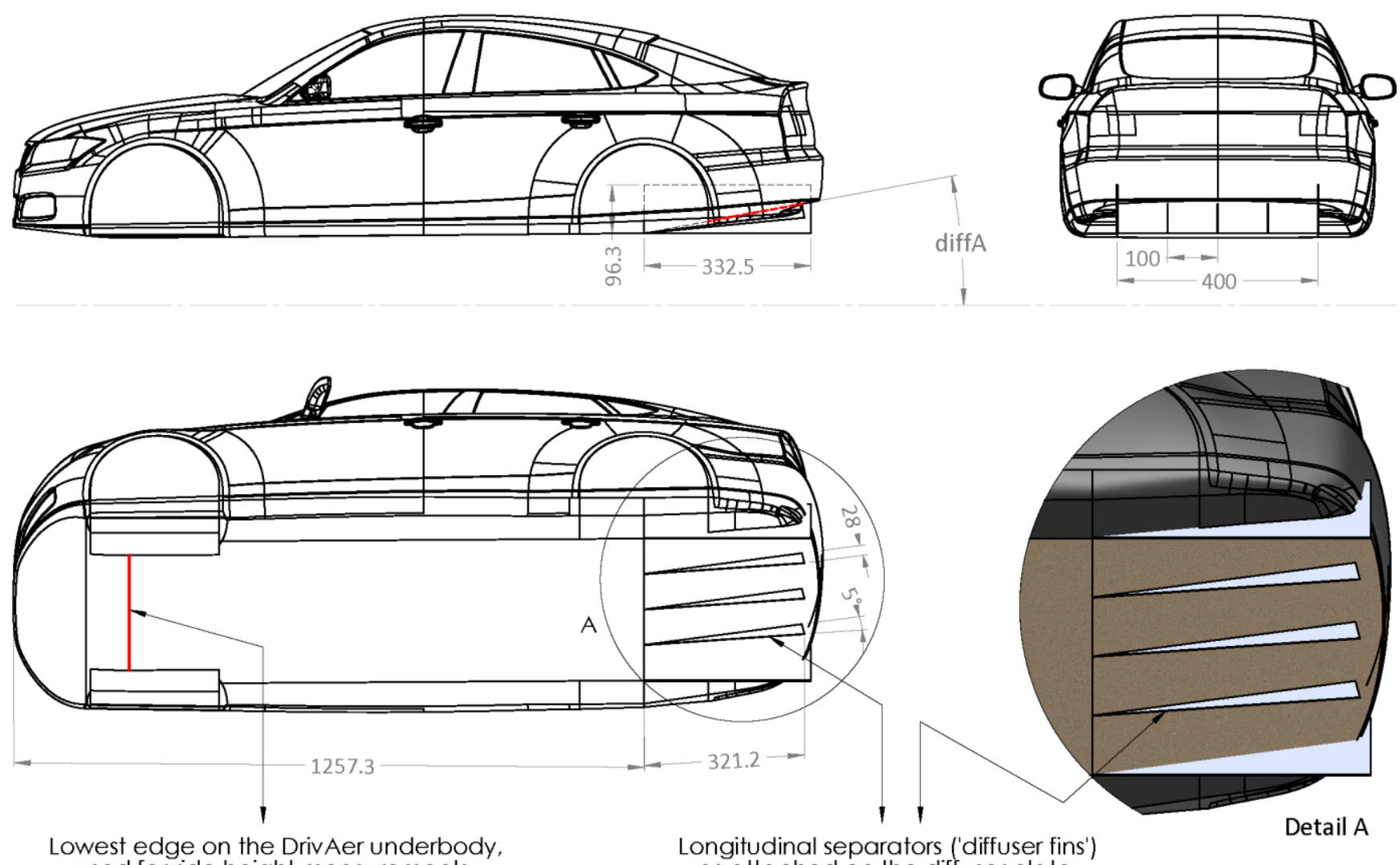
used for ride height measurements.

as attached on the diffuser plate.

Figure 22. Underbody diffuser and longitudinal separators. Dimensions in $\mathrm{mm}$, for a 35\%-scaled DrivAer model. 


\title{
On the aerodynamics of an
} enclosed-wheel racing car: an assessment and proposal of add-on devices for a fourth, high-performance configuration of the DrivAer model

\author{
Soares, Renan Francisco
}

SAE

R. F. Soares, S. M. Goñalons Olives, A. P. Knowles, et al., On the aerodynamics of an enclosed-wheel racing car: an assessment and proposal of add-on devices for a fourth, high-performance configuration of the DrivAer model. WCX18: World Congress Experience, 10-12 April 2018, Detroit, MI, USA. SAE Technical Papers, paper number 2018-04-03 https://doi.org/10.4271/2018-01-0725 Downloaded from Cranfield Library Services E-Repository 